\title{
Metabolic Reprogramming of Non-Hodgkin's B-Cell Lymphomas and Potential Therapeutic Strategies
}

\author{
Jean-Ehrland Ricci* and Johanna Chiche \\ INSERM U1065, C3M, Team Metabolism, Cancer and Immune Responses, Universiteé Côte d'Azur, Nice, France
}

Metabolism is a wide and general term that refers to any intracellular pathways the cell utilizes in order to satisfy its energetic demand and to support cell viability and/or division. Along with phenotypic changes, all mammalian cells including immune cells modulate their metabolic program in order to reach their effector functions. Exacerbated metabolism and metabolic flexibility are also hallmarks of tumor initiation and of tumor cell progression in a complex tumor microenvironment. Metabolic reprogramming is mainly directed by the serine/threonine kinase mTOR (mammalian target of rapamycin). mTOR exists in two structurally and functionally distinct complexes, mTORC1 and mTORC2

OPEN ACCESS

Edited by:

Catherine Pellat-Deceunynck, Centre National de la Recherche Scientifique (CNRS), France

Reviewed by:

Raul V. Duran, Centro Andaluz de Biología Molecular y Medicina Regenerativa (CABIMER),

Spain

Charles Dumontet, Claude Bernard University Lyon 1,

France

*Correspondence: Jean-Ehrland Ricci ricci@unice.fr

Specialty section:

This article was submitted to

Hematologic Malignancies, a section of the journal

Frontiers in Oncology

Received: 26 September 2018 Accepted: 09 November 2018 Published: 04 December 2018

Citation:

Ricci J-E and Chiche J (2018)

Metabolic Reprogramming of Non-Hodgkin's B-Cell Lymphomas and Potential Therapeutic Strategies.

Front. Oncol. 8:556.

doi: 10.3389/fonc.2018.00556 that coordinate environmental signals and metabolic/anabolic pathways to provide macromolecules and energy needed for survival and growth. Activation of mTORC1 is required during development, differentiation and activation of immune cells. Aberrant and persistent activation of mTORC1 is often observed in malignant B cells such as NonHodgkin's (NH) B-cell lymphomas. Here, we review recent insights on cell metabolism and on basic mechanisms of $\mathrm{mTORC} 1$ regulation and metabolic functions. We highlight the distinct mechanisms driving mTORC1 activation in the three most-common types of NH B-cell lymphomas (Diffuse Large B Cell Lymphomas, Follicular Lymphomas, and Mantle Cell Lymphomas), for which the first generation of mTORC1 inhibitors (rapalogs) have been extensively evaluated in preclinical and clinical settings. Finally, we discuss the reasons for limited clinical success of this therapy and focus on potential therapeutic strategies targeting metabolic pathways, upstream and downstream of mTORC1, that can be combined to rapalogs in order to improve patient's outcome.

Keywords: metabolism, Non-Hodgekins lymphoma, mTORC, mammalian target of rapamycin complex, therapeutic strategies, DLBCL-Diffuse large B cell lymphoma, folicular lymphoma, mantel cell lymphoma

\section{INTRODUCTION}

Immunometabolism is an emerging field of research that has already profoundly improved our understanding on how immune cells influence metabolism and vice versa. With the introduction and the success of immune checkpoint inhibitors in cancer treatments (anti-PD1, anti-PDL1, anti-CTLA4) [for review, see (1)], most of the scientific interest was focused on $\mathrm{T}$ lymphocytes due to the ability of certain $\mathrm{T}$ cell subsets to clear pathogens and cancer cells. In contrast, very little attention was given to decipher how the microenvironment influences metabolism of normal B cells during B cell development and how cell metabolism controls B lymphocyte fate and functions during physiological or pathological immune responses. B cells experience several phenotypic changes in 
order to differentiate into plasma cells and memory B cells capable of producing a large amount of antibodies (Figure 1). $\mathrm{T}$ and B-lymphocytes share common characteristics, as they are both able of reprogramming communications between extracellular signals, signaling pathways and metabolism, in order to reach their effectors functions. In immune cells and in cancer cells, this metabolic reprogramming is mainly regulated by the serine/threonine kinase mTOR (mammalian target of rapamycin). mTOR complex 1 (mTORC1) senses environmental changes (fluctuations of growth factors, nutrients, oxygen, immune signals) and orchestrates the cellular responses to enable cell maintenance and functions. Whereas the contribution of mTORC1 to $\mathrm{T}$ cell differentiation is well-established [for review, see (2)], few studies have investigated the role of mTORC1 in B cell development. In the low-oxygenated environment of the bone marrow, $\mathrm{B}$ cell progenitors experience a series of developmental steps to progressively express multiple immunoglobulin receptors (B-cell commitment) that will enable mature $B$ cells to recognize a variety of foreign proteins. At early stages of their development, murine pro- and pre-B cells display a highly active mTORC1 signaling when compared to late pre-B, immature or mature B cells (3). Genetic disruption of mTORC1 activation or chemical inhibition of mTORC1 signaling leads to the accumulation of pre- $\mathrm{B}$ cells that are unable to produce energy levels compatible with B-cell development (3). Once mature, $\mathrm{B}$ cells leave the bone marrow and migrate to the secondary lymphoid organs (spleen or lymph nodes) where they can be activated upon stimulation of their B-cell receptor (BCR) by soluble (T-cell independent activation) or membranebound antigen (T-cell dependent activation) (Figure 1). In the context of T-cell dependent activation (leading to the strongest antibody responses), B cells bind to an antigen via its BCR and present antigenic peptides to $\mathrm{T}$ follicular helpers $\left(\mathrm{T}_{\mathrm{FH}}\right)$, previously stimulated by antigen presenting cells (APC) at the naïve stage. Simultaneously, B cells receive signals from $\mathrm{T}_{\mathrm{FH}}$ cells through co-stimulatory molecules (such as CD40/CD40L for example) and cytokines produced by $\mathrm{T}_{\mathrm{FH}}$. Once $\mathrm{B}$ cells are activated, they differentiate into two-ways. Activated B cells may exit the follicle, proliferate and differentiate, giving rise to shortlived plasma cells producing low-affinity antibodies (IgM or IgG) for early defense against the antigen, while long-lived plasma cells producing high-affinity antibodies are generated (Figure 1). Activated B cells proliferate and the signals provided by the crosstalk between $\mathrm{T}$ and $\mathrm{B}$ cells, help for the development (and the longevity) of germinal centers, where B cells express BCR with different antigen affinities (through somatic hypermutation and class switch recombination) and are selected for antibodies with the greater antigen affinity (antibody affinity maturation step). Antibody affinity maturation is a dynamic process occurring in two distinct zones of the germinal center. In the dark zone, germinal center B (GCB) cells express BCR with different affinities for the antigen and extensively proliferate. Antigendependent signals are delivered in the light zone, where B cells compete with each other for antigen, in contact with APC and $\mathrm{T}_{\mathrm{FH}}$ cells (Figure 1). The cycling of $\mathrm{B}$ cells between the light zone and the dark zone, leads to a positive selection of a specific $\mathrm{B}$ cell clone harboring a BCR capable of binding the antigen with high affinity. During affinity maturation, mTORC1 activity is required in vivo to induce the anabolic program that enables the activated $\mathrm{B}$ cells, proliferation in the dark zone, but it is dispensable when cells have already engaged in cell division (4). Selected B cells leave the germinal centers as high-affinity long-lived plasma cells, which secrete a large amount of clone-specific antibodies, or as memory $\mathrm{B}$ cells (Figure 1).

Non-Hodgkin's (NH) B-cell lymphomas represent $90 \%$ of $\mathrm{NH}$ lymphomas (5) and originate from different stages of B-lymphocyte development and maturation (Figure 1). They consist in a heterogeneous group of diseases that differ at the genetic, histologic and clinical levels. Following the diagnosis, patients with $\mathrm{NH} \mathrm{B-cell} \mathrm{lymphomas} \mathrm{are} \mathrm{primarily} \mathrm{treated} \mathrm{with} \mathrm{a}$ monoclonal anti-CD20 (R, Rituximab) combined with standard chemotherapy approaches (such as CHOP, Cyclophosphamide, Hydroxydaunorubicin, Oncovin, Prednisone). Rituximab is a monoclonal antibody targeting CD20, a plasma membrane phosphoprotein exclusively expressed by B-lymphocytes (normal and malignant) from pre-B cells to memory B cells (Figure 1). Upon binding to its target, anti-CD20 leads to B cell depletion through three main mechanisms: (i) inhibition of intracellular signaling pathways and induction of apoptosis, (ii) activation of the complement, resulting in a complementdependent cytotoxicity (CDC) and/or (iii) recognition of antiCD20 targeted B cells by immune effector cells (mostly natural killers or macrophages), thus inducing antibody-dependent mediated cytotoxicity (ADCC) (6). R-CHOP treatment has significantly improved patients' outcome, however, a significant proportion of patients with aggressive lymphomas such as Mantle Cell Lymphomas (MCL) or Diffuse Large B Cell Lymphomas (DLBCL) are refractory or become resistant to this treatment. Furthermore, indolent Follicular Lymphomas (FL) might experience disease transformation into an aggressive form of NH B-cell lymphoma and remain impossible to treat once the disease has relapsed. The medical need for new therapeutic options targeting refractory/relapsed $\mathrm{NH}$ B-cell lymphomas, remains unmet.

$\mathrm{NH}$ B-cell lymphomas display deregulated mTORC1 activity. In this review we describe the evidence for highly active mTORC1 signaling in the three most-common types of NH Bcell lymphomas: DLBCL, FL, and MCL (Figure 1). Inhibitors of mTORC1 activity (rapalogs) were extensively evaluated in refractory/relapsed DLBCL, FL and MCL and were less successful in the clinical studies than expected from preclinical studies. Rapalogs only gained approval in MCL for which all conventional chemotherapeutic strategies have failed. We highlight therapeutic strategies that can be combined with rapalogs in order to improve the therapeutic benefit for patients with refractory/relapsed $\mathrm{NH}$ B-cell lymphomas.

\section{OVERVIEW ON MAMMALIAN CELL METABOLISM AND ITS REGULATION BY mTORC1 SIGNALING}

\section{Basis on Energetic Metabolism}

All mammalian cells (quiescent or proliferating, normal or cancerous) consume available nutrients at different rates in order to generate metabolic precursors essential for the biosynthesis 


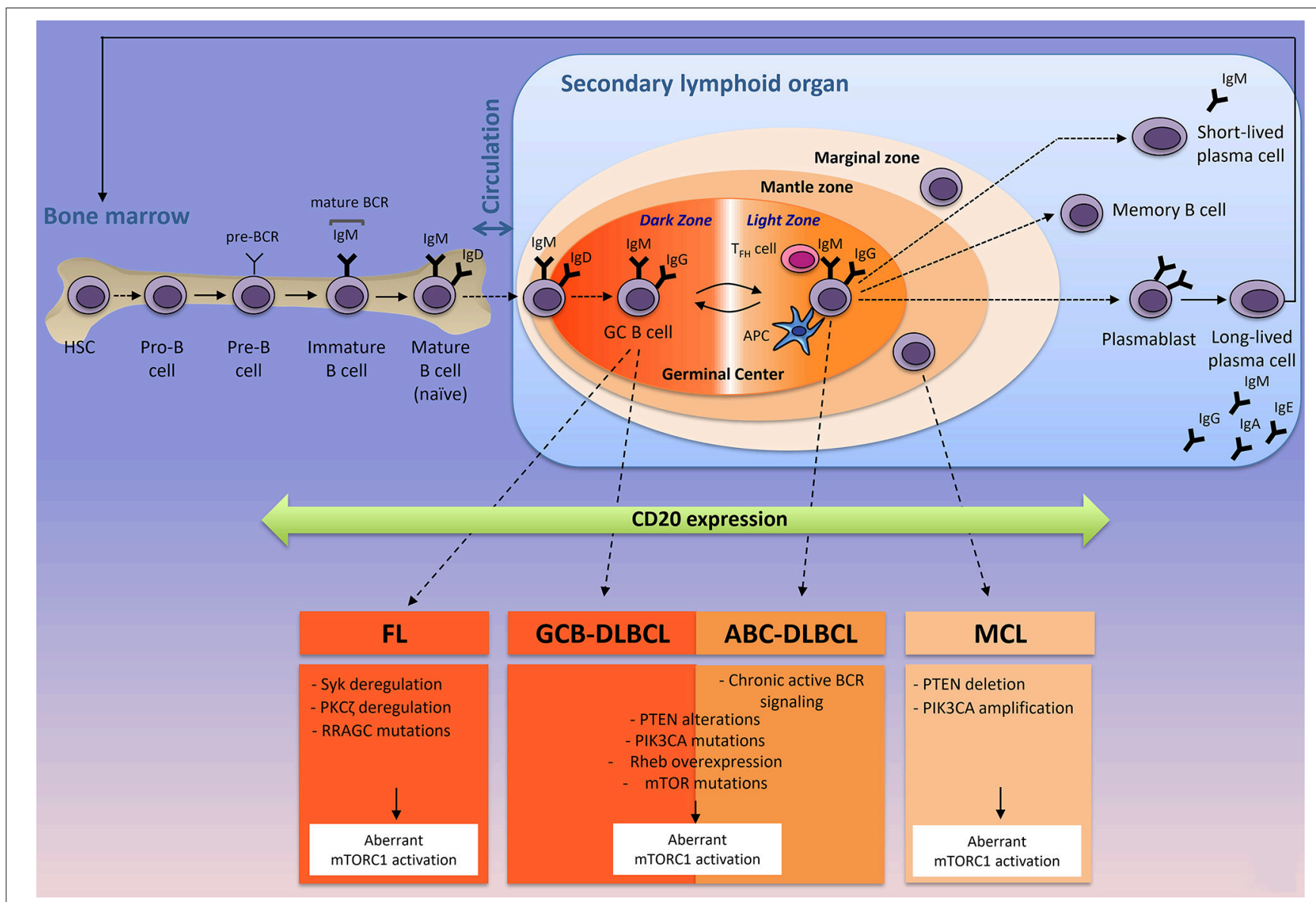

FIGURE 1 | The origin of the three most-common mature B-cell lymphoid neoplasms according to their normal B cells counterparts. Naiive B cells develop in the bone marrow where they generate a B-cell receptor (BCR) and circulate to the secondary lymphoid organs (spleen or lymph nodes) where they are activated in contact with a specific antigen, resulting in a formation of a germinal center. Antibody affinity maturation occurs in the dark zone where B cells extensively proliferate and undergo somatic mutations of the immunoglobulin variable region, and in the light zones, where B cells interact with $\mathrm{T}_{\mathrm{FH}}$ and $\mathrm{APC}$ cells and are selected for a specific clone that has the highest affinity for the antigen. MCL, DLBCL (ABC- and GCB-), and FL are NH B-cell lymphomas arise from mature B-cells in the secondary lymphoid organ. In most of the cases, FL, DLBCL, and MCL express the transmembrane protein CD20 (that is acquired from pre-B to memory stages), targeted by Rituximab (anti-CD20) and harbor different intrinsic factors leading to a constitutive mTORC1 activity. Corresponding intrinsic factors leading to aberrant mTORC1 activation are indicated. APC, antigen presenting cell; $\mathrm{T}_{\mathrm{FH}}$, follicular helper T cell; Ig; immunoglobulin; BCR, B-cell receptor; FL, Follicular Lymphoma; DLBCL, Diffuse Large B Cell Lymphoma; GCB-DLBCL, germinal-center B-cell-DLBCL; ABC-DLBCL, Activated B-cell-DLBCL; MCL, Mantle Cell Lymphoma.

of proteins, lipids, nucleotides and energy (ATP, adenosine triphosphate), thus enabling cell survival/proliferation and functions. Two main metabolic pathways, in two distinct cellular compartments, produce ATP: the glycolysis acts in the cytoplasm and the oxidative phosphorylation (OxPhos), in the mitochondria. Glycolysis converts glucose into pyruvate through a series of 10 step-reactions that transfer phosphate groups from glycolytic intermediates to adenosine diphosphate (ADP) to generate ATP (Figure 2). The pyruvate derived from glycolysis is then converted into lactate (end production of glycolysis) by the lactate dehydrogenase-A (LDH-A), which recycles the oxidized form of nicotinamide adenine dinucleotide (NAD+) in order to provide a continuous glycolytic flux (Figure 2). The bidirectional extrusion of lactic acid ( $\mathrm{H}+$, lactate-) outside the cells is also required to sustain a high rate of glycolysis (such as in muscle cells under exercise or in cancer cells) and is facilitated by monocarboxylate transporters (MCTs) (7) (Figure 2). Glycolysis yield 2 ATP for one molecule of glucose consumed.

The OxPhos metabolism is the route by which the tricarboxylic acid (TCA) cycle and the Electron Transport Chain (ETC) activity are connected to couple oxygen consumption to ATP production in the mitochondria (Figure 2). Mammalian cells can integrate glycolysis and OxPhos metabolism by oxidizing glucose. The pyruvate derived from glycolysis can be redirected to the mitochondria where it is converted into Acetyl-CoA (Ac-CoA) by the pyruvate dehydrogenase complex (PDH). Ac-CoA enters the TCA cycle, which generates reducing equivalents that are transferred to the mitochondrial ETC complexes as NADH (at ECT complex I) or reduced flavins (at complex II and III), thus promoting electron transport across the ECT complexes, consumption of $\mathrm{O}_{2}$ (complex IV) and production of ATP (complex V) (Figure 2). For 1 molecule of 


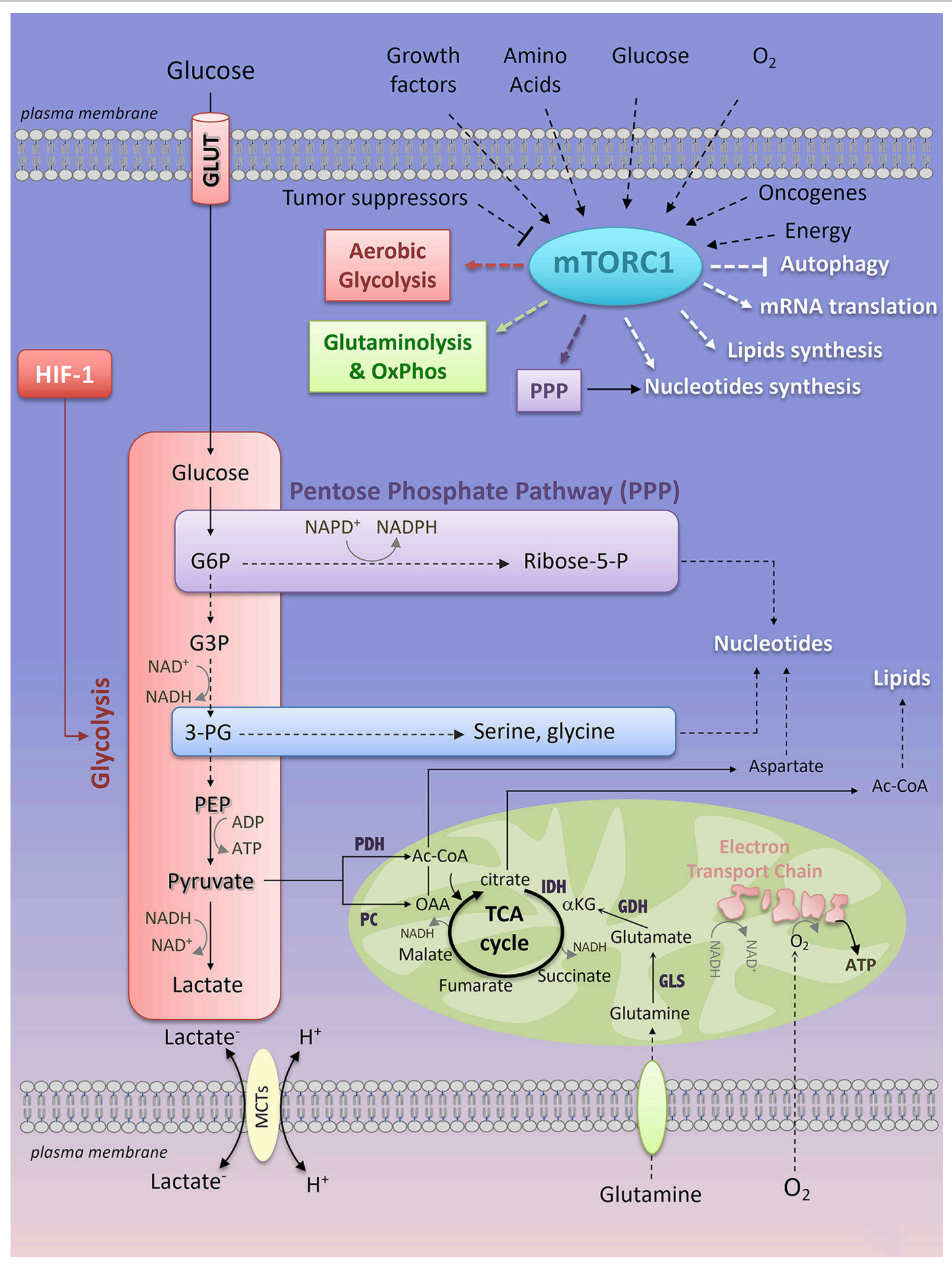

FIGURE 2 | Key interconnected metabolic pathways and their relevance to mTORC1 activation. Extrinsic (growth factors, amino acids, oxygen, glucose) and intrinsic (oncogene, energy levels) factors activate mTORC1 signaling, while tumor suppressors prevent its activation. In turn, mTORC1 enhances glycolysis, through HIF-1-dependent glycolytic program, the pentose phosphate pathway, and glutamine metabolism. mTORC1-dependent regulation of cell metabolism converges through an anabolic program resulting in increased nucleotides, protein and lipid synthesis while inhibiting autophagy. mTORC1, mTOR complex 1; PPP, pentose phosphate pathway; HIF-1, Hypoxia-Inducible Factor-1; LDH, lactate dehydrogenase; PDH, pyruvate dehydrogenase; PC, pyruvate carboxylase; IDH, isocitrate dehydrogenase; GDH, glutamate dehydrogenase; GLS, glutaminase; Ac-CoA, Acetyl-CoA; OAA, oxaloacetate; $\alpha$-KG, $\alpha$-ketoglutarate; G6P, glucose-6-phosphate; G3P, glyceraldehyde-3-phosphate; 3-PG, 3-phosphoglycerate; PEP, phosphoenolpyruvate; Ribose-5-P, Ribose-5-phosphate; ADP, adenosine diphosphate; ATP, adenosine $5^{\prime}$-triphosphate; $\mathrm{NAD}^{+}$, nicotinamide adenine dinucleotide; $\mathrm{NADH}$, reduced form of $\mathrm{NAD}^{+}$; $\mathrm{NADP}^{+}$, nicotinamide adenine dinucleotide phosphate; $\mathrm{NADPH}$, reduced form of $\mathrm{NADP}^{+}$. 
glucose oxidized, OxPhos metabolism consumes 6 molecules of oxygen and yields 38 ATP. Not only glucose, but also fatty acids (through fatty acid oxidation) or glutamine (through glutaminolysis) can be metabolized to provide precursors for OxPhos metabolism. Oxidation of fatty acids generates AcCoA that enters the TCA cycle, leading to TCA anaplerosis and mitochondrial respiration (8). Glutamine is a non-essential amino acid (NEAA) uptaken by a large family of amino acid transporters (9). Once imported into the cell, carbon-derived glutamine serves as a fuel for the TCA cycle anaplerosis. Indeed, glutamine is hydrolyzed into glutamate and inorganic ammonia via the activity of the glutaminase (GLS) (Figure 2). Glutamate is either extruded outside the cells against the cysteine, through the $\mathrm{xCT}$ antiporter (10) or is converted into $\alpha$-ketoglutarate $(\alpha-K G)$ by the glutamate dehydrogenase (GDH), the activity of which is dependent on the essential amino acid (EAA) leucine. $\alpha \mathrm{KG}$ is metabolized in the TCA cycle, thereby supporting OxPhos metabolism (Figure 2). Glutamine is also a nitrogen donor for nucleotide synthesis. The importance of glutamine in an in vitro culture of immune cells and of cancer cell lines derived from various tissues has been extensively reported, thus revealing glutamine as the second most consumed nutrient after glucose. However, in vivo, what glutamine provides to immune cells or to cancer cells remains highly debated and only partially understood. Whereas cultured lung cancer cells consume and metabolize glutamine to support OxPhos metabolism, in vivo glutamine only marginally contributes to TCA cycle anaplerosis and to tumor growth in mice models of lung carcinoma (11) and in patient's lung cancers (12). As a consequence, inhibition of glutaminolysis in vivo (using the GLS inhibitor CB-839, currently under clinical investigation in the treatment of hematologic malignancies and solid cancers including lung cancers) does not affect tumor cell progression (11). Instead, lung cancer cells preferentially use glucose-derived carbons to replenish the TCA cycle (11, 12). Glutamine-derived carbons are not prevalent to TCA cycle anaplerosis in patient-derived glioblastoma xenograft models and in glioblastoma patients $(13,14)$. Additionally, external sources of glutamine are dispensable for Ras-mutated tumors that rather adopted another route of nutrient uptake, a catabolic process named macropinocytosis by which extracellular proteins are internalized into the cells via macrovesicles. Once internalized, the macrovesicles fuse with the lysosomes and the degraded content is a "ready-to-use" amino acid supply (including glutamine) driving tumor metabolism and growth in vitro and in vivo, in mouse models of KRAS ${ }^{\mathrm{G} 12 \mathrm{D}}$-driven pancreatic cancers $(15,16)$. Macropinocytosis was recently observed in human pancreatic cancer tissues $(16,17)$. So far, evidence of tumor glutamine addiction was shown by PET imaging of the glutamine analog $4-{ }^{18} \mathrm{~F}$ - $(2 \mathrm{~S}, 4 \mathrm{R})$-fluoroglutamine $\left({ }^{18} \mathrm{~F}-\mathrm{FGln}\right)$ in preclinical models of glioma and in patients with gliomas (18). Additionally, glutamine metabolism was shown to be essential for NH B-cell lymphomas (human Burkitt cell lines) proliferation under conditions of glucose and oxygen deprivation (19).

Besides glucose, fatty acids and glutamine, other fuels such as lactate, acetate, the NEAA aspartate, asparagine and the EAA leucine, arginine and serine support cell growth in nutrientlimited environments [for details please refer to (20)].

\section{Metabolic Plasticity of Cancer Cells}

Most mammalian cells adapt their metabolism to face unusual environmental conditions. The metabolic flexibility of a cell is a reversible phenomenon that corresponds to a "jump" from a resting metabolic state to the best-adapted metabolic pathway to sustain cellular functions in stressful environments. This metabolic choice has considerable consequences on interconnected metabolic processes and anabolic pathways. Glucose oxidation provides major carbon sources for biosynthesis. Early in the glycolysis pathway, the glycolytic intermediate metabolite glucose-6-phosphate (G6P) connects glycolysis to the non-oxidative branch of the pentose phosphate pathway (PPP), resulting in the production of ribose-5-phosphate required for de novo nucleotides (purine and pyrimidine) synthesis (Figure 2). Through its oxidative branch, PPP also generates NADPH that is essential for the maintenance of the cellular redox status. 3-phosphoglycerate (3-PG) is another branching point that links glycolysis to the synthesis of the NEAA serine and glycine, thereby providing one-carbon source for purines biosynthesis (Figure 2). Glucosederived pyruvate can be converted into Ac-CoA through a reaction catalyzed by the pyruvate dehydrogenase $(\mathrm{PDH})$, or into oxaloacetate (OAA) by the pyruvate carboxylase (PC) and the glutamate and oxaloacetate transaminases (GOT). Ac-CoA contributes to TCA cycle anaplerosis and is also a precursor for fatty acid and cholesterol synthesis, while OAA is a branching point from TCA cycle anaplerosis to the synthesis of NEAA aspartate and asparagine, both of which are required for protein and nucleotide synthesis (Figure 2).

What factors influence the metabolic flexibility? Like wind for bungee jumpers, metabolic requirements of mammalian cells are mainly challenged by fluctuations of nutrients (glucose, EAA, NEAA, and oxygen), growth factors and inflammatory signals in the tissue microenvironment, a fragile ecosystem in which cells from different origins (immune cells, tissue resident cells) compete for substrates (21).

In high altitudes, the metabolism of the whole body adapts to the limitation of oxygen pressure (hypoxia) in the blood (22). In a pathological context, the rapid and persistent expansion of the tumor cells led to an insufficient supply of oxygen in tumor areas that are poorly and inefficiently perfused. In these hypoxic areas, tumor cells restrict ATP production through oxidative metabolism and adapt to this energetic challenge by stabilizing the $\alpha$ subunit of the hypoxia-inducible factor 1 (HIF$1 \alpha$ ), thus increasing the HIF-1-dependent glycolytic program to compensate for the lack of ATP produced by the mitochondria (23). Nevertheless, well-oxygenated cells may also use glycolysis (aerobic glycolysis). This phenomenon has been widely described as a feature of cancer cells, and is best known as the "Warburg effect." Investigations by the Nobel laureate Otto Warburg described that cancer cells produce a larger amount of lactic acid than normal cells, even in the presence of oxygen. He concluded that oxygen is not necessarily required for cancer progression and he interpreted that cancer cells shift their metabolism to 
aerobic glycolysis because mitochondrial respiration is impaired (24). However, numerous studies did not support this hypothesis as they failed to demonstrate mitochondrial dysfunction as a common feature of cancer cells (25). Consequently, in most cancer cells, aerobic glycolysis is not the consequence of defective respiration. Intriguingly, why would cancer cells adopt aerobic glycolysis while it is an inefficient pathway to produce the ATP? Glycolysis allows fast ATP production and a threshold level of ATP is critical for cell survival (25). Moreover, as mentioned above, glycolysis generates a carbon source for de novo nucleotide synthesis, enabling rapid proliferation (26). During adaptive immune responses, metabolic flexibility is required for $\mathrm{T}$ cells to reach their effector functions $(27,28)$. Metabolic characterization of the different $\mathrm{T}$ cell populations revealed the metabolic flexibility of $\mathrm{T}$ cells with relevance to aerobic glycolysis for some $\mathrm{T}$ cell subsets. T helper-17 (Th17) cells engage aerobic glycolysis in vitro to enable their differentiation (29). In contrast, resting memory and regulatory (Treg) $\mathrm{T}$ cells predominantly use OxPhos metabolism (30). Proliferating T cells rely on aerobic glycolysis when activated in vitro (27). Thus, the Warburg effect is not a unique feature of transformed cells and is a mere reflection of cell proliferation influenced by in vitro cell culture conditions.

Cell-cell competition for available substrates is a dynamic process that influences the metabolism of cells. Despite a rapid access to nutrients, oxygenated tumor cells make glucose available for hypoxic glucose-addicted tumor cells to support cancer progression. As a consequence, oxygenated cells recapture hypoxic cells waste (lactate) to use it as a carbon source to supply their own energetic demand (31). Similarly, tumor cells hijack glucose from surrounding immune cells, thus restricting $\mathrm{T}$ cell glucose utilization, $\mathrm{T}$ cell metabolism and anti-cancer immune functions (21). Glycolytic tumor cells also block $\mathrm{T}$ effector cell functions by extruding high quantities of lactic acid, thereby contributing to tumor expansion (32).

\section{Same Tumor Entities, Distinct Metabolic Requirements: Identification of the Tumor Metabolic Heterogeneity}

Several decades of research were dedicated to the understanding of molecular mechanisms regulating the Warburg effect in cancer cells. Oncogenes (c-MYC), loss of tumor suppressors (PTEN, p53) and activating mutations in signaling pathways, regulate glucose uptake and expression of glycolytic enzymes, thus controlling the metabolic switch toward aerobic glycolysis, as observed by Warburg (33).

Although Warburg failed to demonstrate that mitochondrial energetic functions were defective in cancer cells, mutations in the mitochondrial enzymes were later reported in a subset of tumors. As an example, mutations in the TCA cycle enzyme isocitrate dehydrogenase-1 or 2 (IDH1 or IDH2) lead to the accumulation of the oncometabolite 2-hydroxyglutarate (2-HG), responsible for aerobic stabilization of HIF- $1 \alpha$ and subsequent increase in aerobic glycolysis (34). However, genetic drivers of aerobic glycolysis are not a feature of all cancers and some tumors subsets seem not to follow the Warburg scheme. Oxidative metabolism does contribute to tumorigenesis and to cancer progression (35), thus challenging the "Warburg concept." With the development of "omics" technologies, such as metabolomics and fluxomics (the latter consisting in the tracing of a specific isotope to determine the rate of metabolic reactions) several studies established that aerobic glycolysis is not prevalent in tumors when grown in mice or in humans, instead in vivo tumor cells oxidize glucose (36) or lactate (37) to replenish the TCA cycle. Other omics approaches have provided accurate information on gene expression (gene expression profiling, GEP), thereby revealing tumor molecular and metabolic heterogeneity within the same tumor entity. The metabolic heterogeneity was first described in 2005 by a whole-genome array and multiple clustering methods, in diffuse large B cell lymphomas (DLBCL) from patients (38) and it was later confirmed in human DLBCL cell lines by a proteomic approach (39). About $30 \%$ of primary DLBCL harbor a signature of genes involved in mitochondrial metabolism (38). In vitro, human OxPhosDLBCL cell lines rely on palmitate-dependent mitochondrial metabolism and are sensitive to the inhibition of mitochondrial $\beta$-oxidation (39). Since then, growing evidence of tumors relying on OxPhos metabolism to support survival and proliferation were shown in different types of cancers that originate from different tissues such as melanomas (40) pancreatic cancer (41) and lung cancer (42). Moreover, the transcription factor PGC- $1 \alpha$ (PPAR $\gamma$-coactivator- $1 \alpha$ ) involved in mitochondrial biogenesis is a marker of the metabolic state of human melanomas (40).

Such metabolic heterogeneity raises the question whether markers of the metabolic state-that remains to be found-might be clinically helpful in order to exploit the tumor metabolic vulnerabilities with relevant anti-metabolic therapies.

\section{Regulation of Cell Metabolism and Cell Division: Focus on mTORC1 Signaling}

The metabolic program of a cell is a tightly controlled cellular process. The mechanistic target of rapamycin (mTOR), a nontypical serine/threonine kinase of the PI3K (phosphoinositide 3-kinase)-related kinase (PIKK) family, coordinates cell growth and metabolism by sensing growth factors, ATP levels and fluctuations of nutrients, in normal and in transformed cells (Figure 2). When cells encounter environmental changes incompatible with cell division, mTOR activity is shut down to reduce ATP-requiring anabolic processes (protein, nucleotides, and lipids synthesis), until the signals are newly relayed.

\section{Basic Mechanisms of mTORC1 Activation}

mTOR is active in two structurally and functionally distinct multi-protein complexes (mTORC1 and mTORC2) that are highly regulated. The core component of mTORC1 consists in its catalytic subunit mTOR, Raptor (a regulatory protein associated with mTOR, required for correct subcellular localization of mTORC1), mLST8 (mammalian lethal with Sec13 protein 8, involved in the stability of the catalytic domain of mTORC1) and two inhibitory subunits PRAS40 (proline-rich Akt substrate of $40 \mathrm{kDa}$ ) and DEPTOR (DEP domain containing interacting protein). mTORC2 also contains mTOR, mLST8 and DEPTOR but differs from mTORC1 by Rictor (rapamycin-insensitive companion of mTOR) and two regulatory subunits $\mathrm{mSin} 1$ and 
Protor $1 / 2$. The activity of these complexes is driven by the phosphorylation of mTOR at S2448. mTORC1 and mTORC2 are activated by different signals and phosphorylate distinct substrates [for review, see (43)].

While little is understood concerning mTORC2 activation (44), the first two mTORC2 substrates identified so far are PKC $\alpha$ (Protein Kinase $C \alpha$ ), a regulator of actin cytoskeleton $(45,46)$ and Akt (also known as Protein Kinase B, PKB), a serine/threonine kinase involved in cell survival and metabolism (47) (Figures 3, 4).

mTORC1 senses several independent stimuli: growth factors, intracellular ATP levels and extracellular/intracellular nutrients (Figure 3). Briefly, growth factor signals are transmitted from growth factor receptors to the PI3K/Akt pathway. Activated Akt directly phosphorylates the tuberous sclerosis complex (TSC) protein TSC2 on multiple sites, an action that inactivates the heterotrimeric TSC (which consists in TSC1, TSC2, and TBC1D7 protein) a critical regulator of the small G protein Rheb (Ras homology enriched in brain) GTPase. Both TSC and Rheb are co-localized at the surface of the lysosomes. Inactivation of the TSC complex by Akt results in a release of TSC from Rheb, which becomes Rheb-GTP and activates mTORC1 at the surface of the lysosome (Figure 3). The inflammation-activated kinase, the NF$\kappa \mathrm{B}$ regulator IкB $\alpha$ kinase (IKK $\beta$ ) or other growth factor-activated kinases (Ras/Raf/MEK/ERK) also converge on TSC complex inhibition and mTORC1 activation through phosphorylation of TSC1 or TSC2, respectively (48-50) (Figure 3). In contrast, energy stress or hypoxia turn-off mTORC1 activity by activating TSC through induction of the metabolic regulator AMP-activated protein kinase (AMPK) and/or REDD1 (Regulated in DNA damage and development 1) $(51,52)$ (Figure 3). In parallel, AMPK also inhibits mTORC1 through phosphorylation of Raptor (53).

Other extrinsic factors including extracellular sources of glucose stimulate mTORC1 activity in human cancer cell lines cultivated in the presence of growth factors. Under low glucose conditions (relative to cell culture), the glycolytic enzyme GAPDH (glyceraldeyde-3-phosphate dehydrogenase) is no longer engaged in glycolysis and as a "free" enzyme it sequesters Rheb away from mTORC1 (54). Nevertheless, in the absence of amino acids, factors such as growth factors, glucose, and energy levels are not sufficient to activate mTORC1. Upon amino acid stimulation, members of the Ras-GTPase super family (Rag) are converted into their active nucleotidebound state, resulting in a heterodimer of GTP-bound RagA or B with GDP-bound RagC or D that interacts with the multi-protein Ragulator complex (55). Rag-GTPase-Ragulator complex is tethered at the lysosomal surface and serves as a docking site for mTORC1 (Figure 3). Localization of mTORC1 at the surface of the lysosome, close to its coactivator Rheb, is required for mTORC1 activation. Thus, growth factors, in concert with amino acids, regulate mTORC1 activity. Among all amino acids, cytosolic leucine and arginine are sensed upstream of mTORC1 by Sestrin2 and CASTOR1 (Cellular Arginine Sensor for mTORC1), respectively (56-58), and they are dominantly required to support mTORC1 activation outside the lysosome $(59,60)$. In the presence of leucine, glutamine can also activate mTORC1 through glutaminolysis and stimulation of GTP loading of RagB (61). Later, glutamine was found to activate mTORC1 in a Rag GTPase independent manner (62). Overall, intracellular glutamine is exchanged against extracellular leucine through the plasma membrane LAT1-4F2hc transporter, thus indirectly contributing to mTORC1 activation by leucine (63). This process might explain the addiction of tumor cells to glutamine, at least when maintained in vitro.

A second layer of regulation resides inside the lysosome. Arginine is transported into the lysosome by the low affinity amino acid transporter SLC38A9, a transmembrane lysosomal protein that interacts with key components of the lysosomal multi complex machinery, including V-ATPases, Ragulator, Rags, and mTORC1. SLC38A9 expression is required for lysosomal arginine to activate mTORC1 (64). In a similar manner, the plasma membrane-associated leucine transporter LAT1-4F2hc (SLC7A5-SLC3A2) is recruited at the lysosomal surface to uptake leucine into the lysosomes, resulting in mTORC1 activation via lysosomal leucine-dependent stimulation of v-ATPase (65) (Figure 3).

Increased activation of mTORC1 is observed in numerous cancers due to alterations in intrinsic factors upstream of mTORC1 such as loss of function mutations in tumor suppressors (PTEN, Phosphatase and TENsin homolog, TP53, TSC1/2) or gain-of-function mutations in oncogenes (PI3K, Akt, Ras). All those alterations converge to the inactivation of TSC and constitutive active mTORC1 signaling (Figure 3). Genetic and epigenetic alterations driving aberrant $\mathrm{mTORC} 1$ activity in the three most common types of NH B-cell lymphomas is greater detailed in the next section (see also Figure 1).

\section{The Metabolic Functions of mTORC1}

Upon its activation, mTORC1 phosphorylates numerous downstream effectors, which regulate anabolic processes (nucleotide, protein and lipids synthesi, ribosome biogenesis), while suppressing catabolism (autophagy) (Figure 2). The two best-characterized substrates of mTORC1 are the ribosomal p70S6 serine/threonine kinase (S6K1) and the eukaryotic initiation factor (EIF)-4E binding protein (4E-BP1). Respectively, phosphorylation of S6K1 and 4E-BP1 increases mRNA translation initiation and cap-dependent mRNA translation, two extensively reviewed processes impacting on protein synthesis [for more details please refer to (66)]. mTORC1 can also contribute to protein synthesis by modulating the level of amino acids and/or expression of enzymes of the amino acid metabolism. For instance, asparagine sustains protein translation and enables cell proliferation in glutamine-restricted conditions (67). The levels of asparagine synthetase (ASNS) expression and of intracellular asparagine are reduced upon mTORC1 inhibition with rapamycin $(68,69)$.

Proliferating cells require de novo synthesis of nucleotides to enable DNA replication and ribosome biogenesis (where the majority of nucleotides reside). The two families of nucleotides, purine, and pyrimidine, are building blocks for DNA and RNA synthesis. mTORC1 stimulates de novo pyrimidine synthesis through S6K1 phosphorylation of CAD (carbamoylphosphate synthetase) (70), while it regulates de novo synthesis 


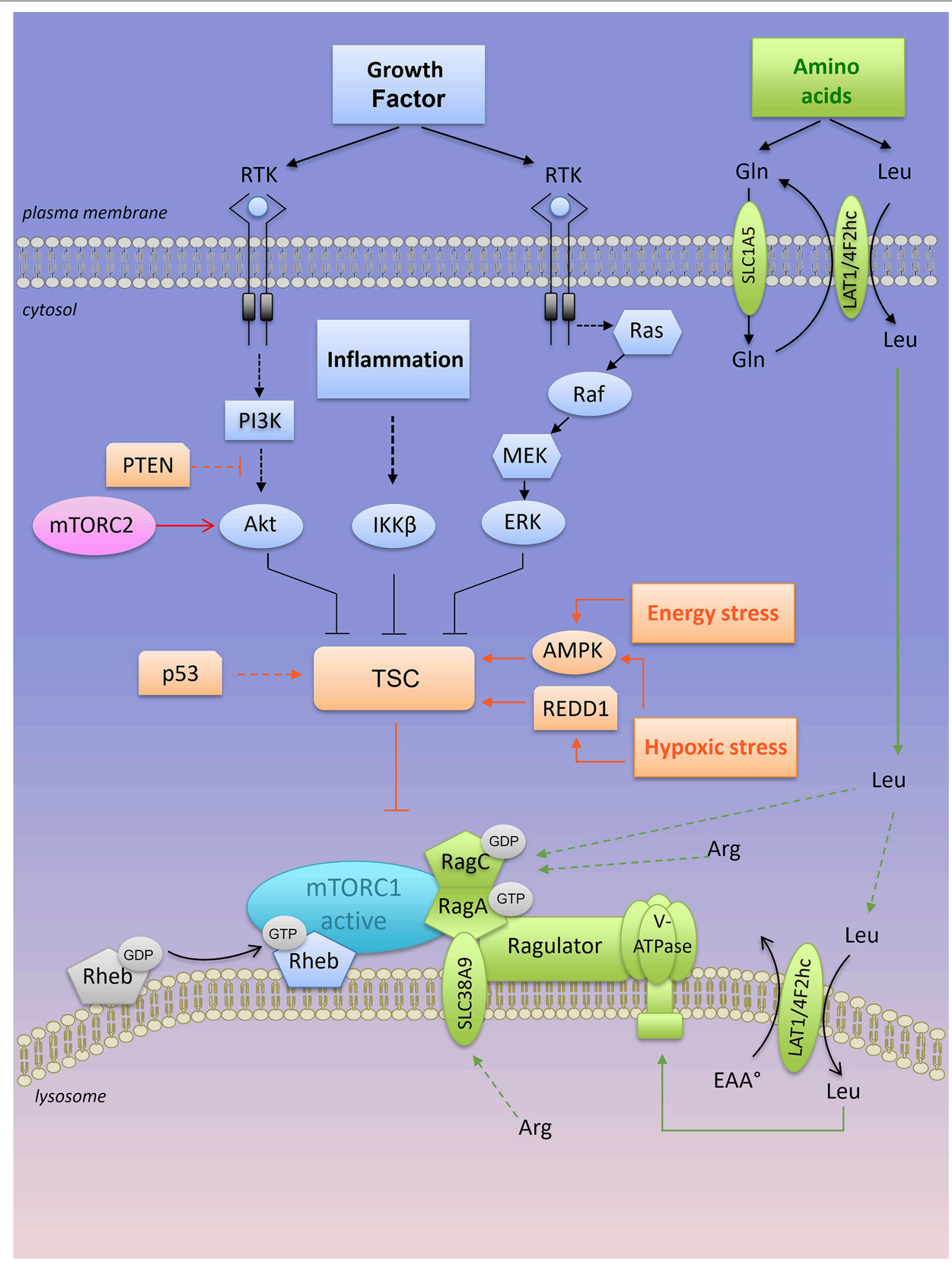

FIGURE 3 | Lysosomal "inside-out" activation of mTORC1. Both growth factors and amino acids are required for a full activation of mTORC1 at the lysosome. Positive regulators of mTORC1 are shown in blue (when activated by growth factors) and in green when activated by amino acids). RTK, receptor tyrosine kinase; mTORC1, mTOR complex 1; mTORC2, mTOR complex 2; TSC, tuberous sclerosis complex; PTEN, Phosphatase and TENsin homolog; AMPK, AMP-activated protein kinase; REDD1, Regulated in DNA damage and development 1; Rheb-GTPase, Ras homology enriched in brain-GTPase; Rag, Ras-related GTP-binding protein; LAT1, L-type amino acid transporter 1; 4F2hc, CD98 heavy subunit protein; Gln, glutamine; Leu, leucine; Arg, arginine. 


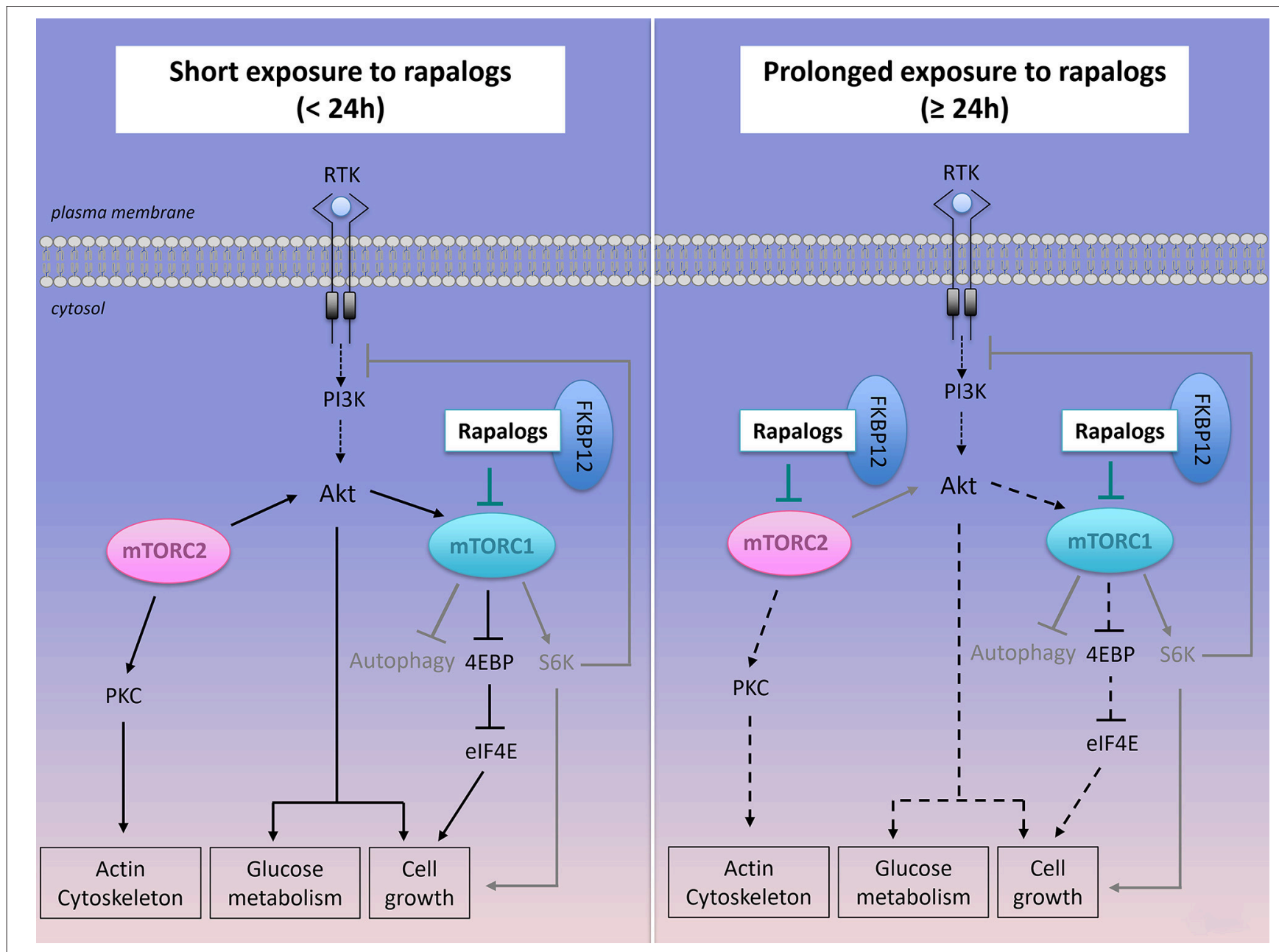

FIGURE 4 | Effect of short or prolonged exposure of rapalogs on mTORC1, mTORC2 activities and on cancer survival and proliferation. Rapalogs form a complex with FKBP12 that inhibits mTORC1 activity, S6K activation but only partially reduces 4EBP signaling. Rapalogs also prevent the feedback inhibition on the PI3K/Akt signaling, thus converging toward Akt activation and cancer cell survival. Prolonged exposure to rapalogs partially inhibits mTORC2 assembly and mTORC2 functions on Akt signaling.

through ATF4 (Activating Transcription Factor 4)-dependent expression of the mitochondrial enzyme MTHFD2 (Methylene Tetrahydrofolate Dehydrogenase 2) (71). Both purine and pyrimidine synthesis require glucose-derived ribose-5-P that is generated by the PPP (Figure 2).

To meet the anabolic demand of proliferating cells (in physiological or pathological conditions), mTORC1 increases the rate of several metabolic pathways including glycolysis, the oxidative arm of the pentose phosphate pathway, lipid synthesis (72) and mitochondrial metabolism $(73,74)$ (Figure 2). mTORC1-dependent increase in cap-dependent translation of HIF- $1 \alpha$ mRNA is sufficient to stimulate HIF-1-dependent glycolytic reprogramming in aerobic conditions, thus positioning the mTORC1/HIF-1 axis as a central mechanism of the Warburg effect. mTORC1 activates the oxidative arm of the PPP by regulating expression of genes involved in this metabolic pathway. De novo synthetized lipids are required for formation of new membranes. In a S6K-dependent or independent manner,
mTORC1 activates SREBP1 (Sterol Regulatory Element-Binding Protein-1), a transcription factor regulating genes encoding for lipogenic enzymes of fatty acid and sterol biosynthesis $(72,75)$. Other effectors of mTORC1 contribute to oxidative metabolism. In skeletal muscle cells, inhibition of mTORC1 reduces he mitochondrial membrane potential, oxygen consumption and mitochondrial ATP as a consequence of a decrease in the genes involved in PGC-1 $\alpha$-regulated mitochondrial biogenesis (73). In acute $\mathrm{T}$ cell leukemias, mTORC1 has immediate functions on mitochondrial respiration and this regulation requires mTORC1-dependent phosphorylation of the anti-apoptotic protein $\mathrm{Bcl}-\mathrm{xL}$ at the outer membrane of the mitochondria (69). In addition, mTORC1 stimulates mitochondrial biogenesis and mitochondrial energetic functions, by regulating $4 \mathrm{E}-\mathrm{BP}-$ dependent translation, in a breast cancer cell line (74). Furthermore, mTORC1 promotes glutaminolysis and glutamine anaplerosis by increasing (i) GLS expression through S6K1dependent control of c-Myc translation (76), and (ii) GDH 
activity, through repression of the mitochondrial Sirtuin SIRT4 that inhibits GDH (77).

Collectively, studies on mTORC1 regulations and functions in normal and in malignant cells highlight a regulatory feedback loop between mTORC1 and metabolic pathways. Consequently, drugs that would target mTORC1 and/or cancer cell metabolism are expected to impair tumor progression and to significantly improve patient survival.

\section{TARGETING mTORC1 SIGNALING IN NON-HODGKIN'S B-CELL LYMPHOMAS: RATIONALE AND CLINICAL RESULTS}

Direct and indirect evidence of active mTORC1 signaling have been reported in several types of NH B-cell lymphomas and correlated with tumor cell proliferation and resistance to immuno-chemotherapy, thus providing a rationale for testing mTOR-targeted therapies in refractory/relapsed $\mathrm{NH}$ B-cell lymphomas. Here, we focus on tumor intrinsic factors leading to aberrant mTORC1 signaling in the three most common types of NH B-cell lymphomas, the high-grade MCL and DLBCL and the low-grade FL, and describe preclinical and clinical studies evaluating rapalogs (mTOR inhibitors) in the treatment of refactory/relapsed MCL, DLBCL and FL (Table 1).

\section{Aberrant Activation of mTORC1 in NH B-Cell Lymphomas \\ Diffuse Large B Cell Lymphomas}

Diffuse Large B Cell Lymphomas (DLBCLs) represent the most common and aggressive type of B lymphomas with $30-40 \%$ of the newly diagnosed NH B-cell lymphomas (WHO classification of tumors 2011) (5). DLBCLs are a genetically heterogeneous group of tumors, often associated with a deregulation of BCL2 and/or BCL6 and/or MYC genes, classified into specific subtypes that differ at the level of biology, histology and the clinical level. Compared to CHOP chemotherapy, R-CHOP immunochemotherapy has significantly improved the overall survival (OS) and the progression-free-survival (PFS) of patients with DLBCL, by $10-15 \%$ (84). However, $30-40 \%$ of patients suffering from DLBCL still experience therapeutic failure or relapse during R-CHOP therapy. Gene expression profiling has improved our understanding of DLBCL biology by classifying DLBCLs based on their cellular origin (Figure 1). Germinal center B-cell (GCB)DLBCL shares a transcriptional profile similar to that of normal germinal center $\mathrm{B}$ cells, activated $\mathrm{B}$-cell (ABC)-DLBCL expresses genes that are up regulated during the activation of normal $B$ cells and Unclassified-DLBCL are distinct from the GCB or the $\mathrm{ABC}$ transcriptional profiles (85) (Figure 1). So far, there are limiting data demonstrating direct evidence of aberrant mTORC1 signaling in DLBCL biopsies. Immunohistochemistry (IHC) staining of phosphorylated-S6 protein (p-S6), one of the most sensitive targets of mTORC1, identified $62 \%$ of mTORC1 active DLBCL with a significant association with non-GCBDLBCL (80\%), while only $10 \%$ GCB-DLBCL stained positive for p-S6 (86). Consistent with the outcome of ABC-DLBCL, patients with mTORC1 active DLBCL who are treated with RCHOP have an unfavorable outcome compared to those with mTORC1 inactive DLBCL (negative p-S6 staining) who show a strikingly long OS (60 months) (86). Mutations in mTOR (mostly missense mutations and truncating mutations) were reported in approximately $7 \%$ of human DLBCL, regardless of the DLBCL molecular subtypes (87). Consistently, knockout of mTOR impairs proliferation of ABC- and GCB-DLBCL lines (87). As for MCL, numerous indirect evidence of highly active mTORC1 signaling are demonstrated upstream of mTORC1 in DLBCL biopsies. Human primary DLBCL samples express heterogeneous levels of Rheb (mRNA and protein) and a high expression of Rheb is associated with aberrant activation of mTORC1 (88). Whether Rheb is differentially regulated in the specific molecular class of DLBCL remains unknown.

PTEN alterations were described in $10 \%$ of primary DLBCL and in 17\% of DLBCL cell lines (89). PTEN loss is prevalent in GCB-DLBCL rather than ABC-DLBCL (90), a characteristic that was confirmed in other patient cohorts $(91,92)$. PTEN mutations are reported in $10.6 \%$ of DLBCL (12\% of GCB-DLBCL and $9 \%$ of $\mathrm{ABC}-\mathrm{DLBCL}$ ) and correlate with the induction of genes involved in the regulation of Akt/mTOR signaling and metabolism (92). DLBCL harboring PTEN mutations do not significantly overlap with the cases exhibiting PTEN loss. Clinically, PTEN deletion or mutations are independent prognostic factors for poorer OS and PFS upon R-CHOP treatment in Akt activated DLBCL $(92,93)$. Less frequent, mutations in the PIK3CA gene or amplifications of PIK3CA are observed in 1.3-12\% of DLBCL (93-96) and they are mutually exclusive with PTEN loss, which further define another PI3K/Akt/mTOR-regulated DLBCL subset (94). Importantly, PIK3CA mutations were undetected in a wide variety of human DLBCL cell lines (94), suggesting a heterogeneous mode of mTORC1 regulation that must be studied or at least confirmed in human primary samples rather than in human DLBCL cell lines.

Independently of Akt or MEK/ERK activation, mTORC1 signaling is constitutively activated in a fraction of GCB-DLBCL cells lines (and in Burkitt cell lines) (97) and in most of the ABCDLBCL cell lines (98) (Figure 1). One hallmark of ABC-DLBCL is a constitutive activation of the NF- $\kappa B$ pathway (99) due to (i) mutations in NF-KB components CARD11 (100), A20 (101) or Myd88 (102) and/or (ii) chronic activation of the B-Cell Receptor (BCR) (as a result of mutations of in the BCR subunits CD79A/B) and downstream kinases $(103,104)$. In ABC-DLBCL, different scenarios regulate mTORC1 activation. Downstream of the BCR, the tyrosine kinase BTK (Bruton's Tyrosine Kinase) and the key NF- $\kappa B$ regulator I $\mathrm{B}$ kinase, IKK $\beta$, are required to integrate BCR and mTORC1 signaling (98). In a fraction of ABC-DLBCL cell lines, the serine/threonine kinase PIM2 (Proviral integration site for Moloney murine leukemia virus-2) is upregulated to sustain mTORC1 signaling (98). Overall, although regulated differently, mTORC1 signaling is activated in both $A B C$ and GCB-DLBCL.

As previously discussed, whole genome arrays identified three other distinct DLBCL subsets: the oxidative phosphorylation (OxPhos) cluster, which is significantly enriched in genes involved in mitochondrial metabolism; the $\mathrm{B}$ cell receptor (BCR) signature, characterized by an up-regulation of cell-cycle 
TABLE 1 | Summary results of phase II and III studies evaluating the effect of rapalogs as a single agent in the treatment of refractory/relapsed NH B-cell lymphomas.

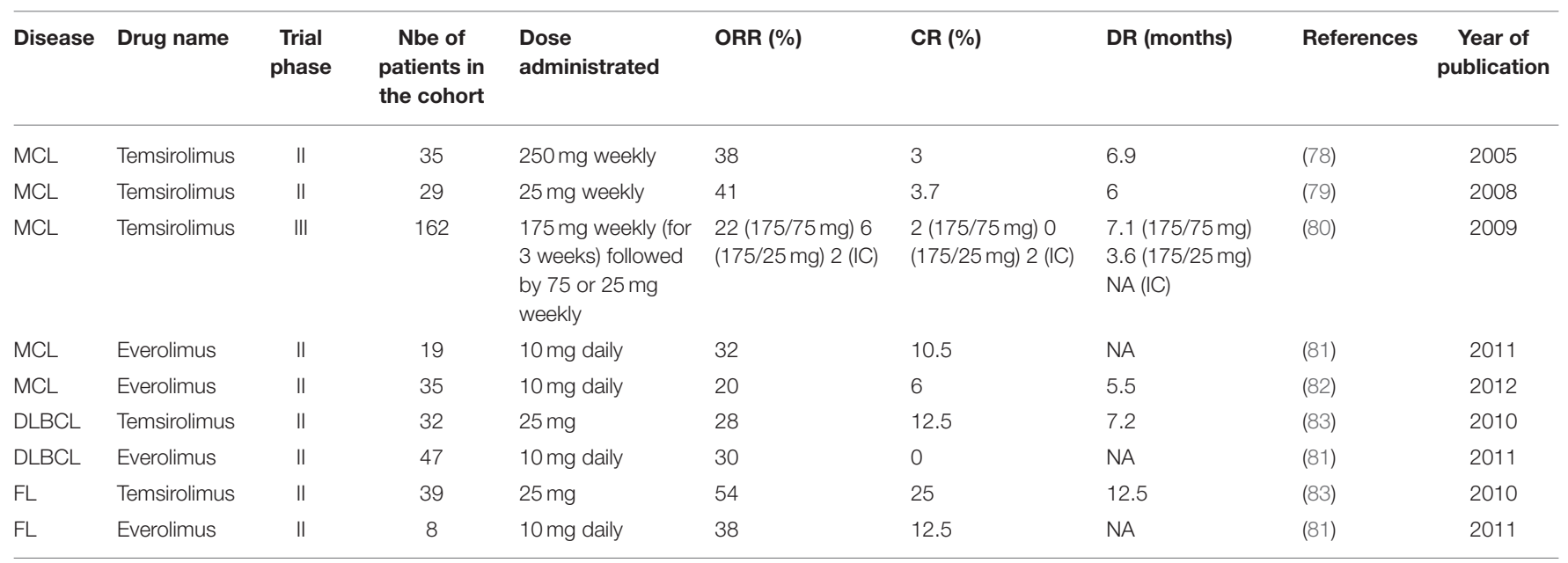

ORR, overall response rate; CR, complete response; DR, duration response; MCL, Mantle Cell Lymphoma; DLBCL, Diffuse Large B Cell Lymphoma; FL, Follicular Lymphoma; IC, investigator's choice; NA, not available.

regulatory genes and BCR components, later associated with glycolytic metabolism; and the Host Response (HR) cluster displaying components of the T-cell receptor and of molecules implicated in T/NK cell activation $(38,39)$. Consistent with the metabolic functions of mTORC1 involved in both OxPhos and glycolytic metabolism and with the mTORC1 activation observed in both ABC and GCB-DLBCL, it appears that cell-oforigin $(\mathrm{COO})$ and $\mathrm{BCR} / \mathrm{OxPhos}$ classifications are independent. However, it would be interesting to determine the extent to which mTOR signaling (mTORC1 and mTORC2) is induced in the BCR- and OxPhos-DLBCL, since unlike the BCR cluster, OxPhos-DLBCL do not express functional BCR. In addition, what specific aspects of their respective metabolism route contribute to mTORC1 activation in each cluster remains unknown. More recently, the loss of the tumor suppressor PP2A (serine/threonine protein phosphatatase 2A) defined another metabolic subset in B malignancies such as DLBCL, which repress the PPP and its corresponding anti-oxidant protection, thereby utilizing glucose-derived carbon though glycolysis (105).

\section{Follicular Lymphomas}

Follicular Lymphomas (FL) is the second most common type of $\mathrm{NH}$ B-cell lymphomas (30\%) (5). It is an incurable malignancy with a median survival of $8-10$ years. FL are low-grade germinal center B lymphomas accompanied by an immune cell infiltrate in the tumor microenvironment. FL are clinically characterized by an initial indolent phase often sensitive to Rituximab-based therapies, that might precede disease transformation into an aggressive form of lymphomas (DLBCL) in $30-40 \%$ of the cases (106), a risk that is not decreased by early initiation of the treatment. Neoplastic B cells quite systematically (90\%) harbor the $t(14 ; 18)$ translocation, which recombines BCL2 gene located at $18 \mathrm{q} 21$ with the immunoglobulin $(\mathrm{Ig}) \mathrm{H}$ chain joining region at $14 \mathrm{q} 32$, leading to $\mathrm{Bcl} 2$ overexpression and apoptosis escape, a critical event in the development of FL. Other cytogenetic and epigenetic alterations enhancing cell growth and metabolism accompanied this translocation, such as in MYC, TNFRSF14, or EZH2 (107). Similar to the mutations found in DLBCL, frequent mutations in signaling pathways including NF- $\kappa$ B are observed in FL. mTORC1 activity in FL is identified by a positive IHC staining of phosphorylated-S6K compared to tonsillar B cells issued from healthy donors (108). In FL, Syk activity is a critical regulator of mTORC1 signaling and independent of Akt activation (108). Activity of PKC $\zeta$ also contributes to aberrant mTORC1 signaling in this disease $(109,110)$. Interestingly, somatic mutations in components of the mTORC1 complex were specifically enriched in FL (17\%) (111), rarely in DLBCL $(<2 \%)(87,111)$, while absent in other NH B-cell malignancies (111). These mutations occur in the gene RRAGC encoding a Ras-related GTP-binding protein (RagC). As a functional consequence, FL expressing RagC mutants increase Raptor binding, thus reinforcing mTORC1 signaling even in the absence of amino acids (111). While some pathways activating mTORC1 have been characterized in FL, the metabolism of those lymphomas remain unexplored. Such metabolic characterization of FL should help to understand the metabolic changes that might occur during FL transformation, a process which remains an open question.

\section{Mantle Cell Lymphomas}

Mantle Cell Lymphoma (MCL) is an aggressive and incurable lymphoma representing 5-10\% of the NH B-cell lymphomas. Most patients with MCL are treated with Rituximab-based therapies such as R-CHOP. Unlike patients with other NH B-cell lymphomas, the outcome of patients with MCL is not improved following R-CHOP treatment (112), and the median overall survival (OS) still varies from 3-4 years. MCL are characterized by a $t(11 ; 14)(\mathrm{q} 13 ; \mathrm{q} 32)$ chromosomal translocation leading to the juxtaposition of the cyclin D1 gene on the chromosome 11 to the $\mathrm{IgH}$ chain enhancer region of the chromosome 14, thus leading to overexpression of the cyclin D1 mRNA and protein (113). Translation of the cyclin D1 mRNA is likely to be regulated by the mTORC1/4E-BP1 signaling axis (114). Constitutive activation of 
mTORC1 is observed in several human MCL cell lines in vitro (81). PTEN loss is reported in 65\% of MCL patients displaying increased cyclin D1 translation (115) and it correlates with the constitutive activation of Akt/mTORC1 signaling in MCL patients and in human MCL cell lines (116). Furthermore, $68 \%$ of MCL patients and human MCL cell lines display an amplification of the PI3K catalytic subunit $\alpha$ (PI3K-p110 $\alpha$ ), encoded by the PIK3CA gene (117). An increased PI3KCA gene copy number is significantly associated with Akt phosphorylation and is mutually exclusive with PTEN loss (117) (Figure 1).

Identification of mTOR active B lymphomas seems to define a group of therapy-resistant tumors, thus linking mTOR activity to an unfavorable outcome for patients and providing a strong rationale for preclinical and clinical evaluation of mTOR-targeted therapies in refractory/relapsed NH B-cell malignancies.

\section{Targeting mTOR Signaling in NH B-Cell Lymphomas: From Preclinical Evidences to the Clinic}

Rapamycin is a highly potent and selective inhibitor of mTORC1. It interacts and forms a complex with the $12 \mathrm{kDa}$ FK506binding protein (FKBP12), which limits the access of substrates to the mTORC1 kinase active site. Rapamycin acts as an allosteric inhibitor of mTORC1 phosphorylation activities that are critical for proliferation $(43,118)$. Even if rapamycin itself is not able to inhibit mTORC2, long-term exposure to this drug might affect them TORC2 complex assembly and signaling in some cell types $(45,119)$ (Figure 4). Rapamycin was first approved in 2000 by the Food and Drug Administration (FDA) as an immunosuppressive agent for the prophylaxis of organ rejection in renal transplant patients. Due to the poor solubility and pharmacokinetics of rapamycin, a first generation of mTOR inhibitors, rapalogs (rapamycin analogs), were developed and evaluated in preclinical and in clinical studies. Phase 1 studies demonstrated that rapalogs induce manageable adverse effects such as asthenia, thrombocytopenia, microsites, hyperglycemia and hyperlipidemia. In 2007 and 2009, the FDA approved Temsirolimus (CCI-779, intravenously delivered) and Everolimus (RAD001, orally bioavailable), two water-soluble rapalogs, for the treatment of advanced renal cell carcinoma. In 2009, Temsirolimus was approved by the European Union for the treatment of refractory/relapsed MCL.

\section{Preclinical Evaluations of Rapalogs in the Treatment of DLBCL, FL, and MCL (in vitro and in vivo Studies)}

Numerous studies demonstrated that the inhibition of mTORC1 with rapalogs induces cytostatic effects rather than cytotoxic responses in human DLBCL, FL, and MCL cell lines in vitro $(81,108,115,120-122)$. Rapalogs restrain cell proliferation of DLBCL regardless of the COO classification, and of the genetic alterations (98), a notion that is not sustained by the conclusions of a phase 2 study in patients with refractory/relapsed DLBCL treated with Everolimus (83). This raises a question about the sensitivity of cultured DLBCL cell lines to mTORC1 inhibition, as it might be the result of in vitro culture conditions that are promoting mTORC1 activity.
In vivo efficacy of Everolimus was evaluated in a genetically engineered mice model of $M Y C$-induced lymphomagenesis, in the E $\mu-M Y C$ mice (123). E $\mu-M Y C$ mice develop spontaneous $\mathrm{NH} B$ lymphomas in 2-20 months after birth. They mimic a genetic feature of human Burkitt lymphomas (which harbor MYC translocation in most cases) and present morphologic characteristics close to human lymphoblastic lymphomas overexpressing MYC. Giving rise to immature B cells, E $\mu$ - MYC lymphomas do not recapitulate features of other human $\mathrm{NH}$ B-cell lymphomas. Nevertheless, those lymphomas are unique at the molecular and metabolic levels, similar to human biopsies of NH B-cell lymphomas. Importantly, malignant $\mathrm{E} \mu-M Y C$ cells can be easily transferred into WT syngeneic immuno-competent recipient mice in order to validate candidate cancer genes and to assess therapy efficacy (124). In transgenic mice, mTORC1 activity is required to initiate malignant transformation of B-lymphocytes (125). Daily administration of Everolimus (5 $\mathrm{mg} / \mathrm{kg}, 6$ days per week) significantly improves $\mathrm{E} \mu-M Y C$-bearing mice survival (upon adoptive transfer of E $\mu-M Y C$ cells) and the median OS widely varies from one $\mathrm{E} \mu-\mathrm{MYC}$ lymphoma to another (125). The heterogeneity of Everolimus responses in vivo is likely related to the individual genetic alterations and the anti-apoptotic properties of each $\mathrm{E} \mu-M Y C$ lymphoma. In agreement with in vitro studies, in vivo Everolimus activity is associated with a G1 cell cycle arrest but not with apoptosis. Importantly, while reducing the proportion of malignant $\mathrm{B}$ cells overexpressing MYC, Everolimus neither affects the number of mature $\mathrm{B} 220+\mathrm{CD} 19+\mathrm{B}$ cells of the bone marrow nor of the spleen in WT nor in E $\mu-M Y C$ mice (125). Moreover, despite its known function as an immunosuppressive agent, Everolimus treatment does not reduce the proportion of immune cells such as macrophages, activated $\mathrm{T}$ cells and NK cells both in WT and in E $\mu-M Y C$ mice, which demonstrates the specific effect of mTORC1 inhibition in tumor cells, while keeping the anti-cancer immune capacity of the mice intact (125).

Genetic mouse models recapitulating human genetic features of FL have been established $(126,127)$ but they are not used for preclinical studies because of their complexity and of their time to tumor development. Recently, patientderived xenograft (PDX) models were established from different types of NH B-cell lymphomas. PDX models retain the similar genetic, histologic and clinical features of the original patient lymphomas and are compatible with preclinical studies on treatment-naïve or treatment-resistant tumors (128).

Collectively, the use of rapalogs as a single agent in the treatment of refractory/relapsed DLBCL, FL and MCL provided encouraging results in preclinical settings that supported further investigations in the clinic.

\section{Clinical Evaluation of Rapalogs Efficacy in the Treatment of Refractory/Relapsed NH B-Cell Lymphomas}

In the view of the therapeutic emergency, refractory/relapsed MCL were the first B lymphoid neoplasm for which rapalogs 
(Temsirolimus and Everolimus) were evaluated as singleagent in clinical settings (78-82). Phase II trials demonstrated significant effects of each rapalog alone, with $20-40 \%$ of overall response rates (ORR), cases complete responses (CR) (3$10 \%$ ) and manageable toxicities (Table 1). In a phase III trial, Temsirolimus was administrated at a dose of $175 \mathrm{mg}$ weekly, over 3 weeks, followed by either $75 \mathrm{mg}(175 / 75 \mathrm{mg})$ or $25 \mathrm{mg}$ $(175 / 25 \mathrm{mg})$ weekly (80). Each patient group was compared to patients treated with a single chemotherapeutic agent of the investigator's choice. Strikingly, ORR was 22 and 2\% for patients treated with Temsirolimus $175 / 75 \mathrm{mg}$ or investigator's choice, respectively (80). Despite a significant improvement of OS, PFS was significantly increased and therapeutic responses occurred in patients relapsing after several treatment lines with a Rituximab-containing regimen. This study ultimately led to the European Union approval (2009) of Temsriolimus as a single agent for the treatment of refractory/relapsed MCL.

Later, Temsirolimus demonstrated a substantial and significant anti-tumor activity in other refractory/relapsed NH B-cell lymphomas, such DLBCL and FL $(81,83)$ (Table 1). ORR was 28 and 54\% for DLBCL and FL, respectively. CR (12 and 25\%) and duration responses (7 and 12.5 months) were also higher in patients with FL than in those with DLBCL (83). These findings were also confirmed in a phase II study evaluating Everolimus in relapsed $\mathrm{NH}$ B-cell lymphomas (81).

Collectively, phase II trials indicated a more potent effect of rapalogs in inducing ORR and CR in low-grade lymphomas (FL) than in high-grade lymphomas (DLBCL or MCL) (Table 1). As FL arises from GCB cells, it might suggest that malignant $\mathrm{B}$ cell origin can influence the response to mTOR-targeted therapies. Further investigations would be needed to determine, for instance, the prognostic of ABC- and GCB-DLBCL treated with rapalogs in order to confirm that DLBCL- transformed from FL, i.e., mostly GCB-DLBCL, might be more sensitive than nonGCB-DLBCL to rapalogs (83). This will be helpful to advance progress on the use of mTOR-targeted therapy in the treatment of FL and DLBCL.

\section{ONGOING AND FUTURE THERAPEUTIC STRATEGIES TARGETING MTORC1 IN NH B-CELL LYMPHOMAS \\ Rational to Combine Rapalogs With Other Therapeutic Approaches}

Although significant, the responsiveness of $\mathrm{NH}$ B-cell lymphomas to rapalogs remains modest in preclinical and in clinical settings. Consequently, rapalogs were clinically approved in only one type of $\mathrm{NH}$ B-cell lymphomas, the relapsed/refractory MCL for which standard therapies have failed. Explanations for this low efficacy can be collected from the molecular studies on tumor heterogeneity and they have to be taken into consideration with the intention of proposing novel therapeutic strategies combining rapalogs with relevant agents in order to improve patient's outcome.
Knowing the role of mTORC1 and its downstream effectors in controlling processes required for cell survival, one expects to see an induction of cell death when rapalogs were used as a single agent. However, rapalogs only reduce cell proliferation and as soon as the treatment is discontinued, proliferation of tumor cells resumes (129). The cytostatic (rather than cytotoxic) effect of rapalogs has been described in many preclinical studies (in vitro and in vivo) using a variety of cancer cell lines, including NH B-cell lymphomas and it can be explained by two main mechanisms of cellular adaptations occurring upstream or downstream of mTORC1, thus raising two main potential therapeutic strategies to collapse tumor growth.

Firstly, the limited clinical success of rapalogs is likely related to mTORC1 upstream molecular events. Rapalogs release the mTORC1-regulated negative feedback loop on the upstream PI3K/Akt signaling (Figure 4). Sustained activity of mTORC2 also contributes to enhanced phosphorylation of Akt. Combined molecular events induce hyperphosphorylated Akt, which in turn does contribute to cell metabolism and survival in rapalogstreated cells in many cancer cells lines, including human DLBCL cell lines (130). A second generation of mTOR inhibitors (ATP competitive inhibitors) have been developed to directly block the ATP-binding pocket of both mTORC1 and mTORC2, thus leading to inhibition of their catalytic activity. Since mTOR and PI3K share similarities in their sequence, ATP-competitive inhibitors block both kinases activities. As expected, such dual $\mathrm{PI} 3 \mathrm{~K} / \mathrm{mTOR}$ inhibitors have higher efficacy than rapalogs in aggressive NH B-cell lymphomas in vitro and in vivo (131) but they have raised concerns of dose-limited toxicities that are thought to be linked to their low selectivity toward mTORC1 $(132,133)$.

Secondly, signaling events downstream of mTORC1 represent a second drawback of rapalogue therapy. Indeed, rapalogs only partially prevent the phosphorylation of certain mTORC1 substrates (Figure 4). For instance, they have a limited effect on 4E-BP1 phosphorylation while they abolish S6K phosphorylation. This was observed in several human cancer cell lines including human DLBCL cell lines, regardless of the $A B C$ or GCB classification $(122,130,134)$. Importantly, rapamycininsensitive phosphorylation of $4 \mathrm{E}-\mathrm{BP} 1$ is sufficient to stimulate cap-dependent translation $(122,134)$. Mechanistically, specific substrate sequences near the phosphorylation site of mTORC1, influence mTORC1 kinase activity and correlate with resistance to rapamycin-induced suppression of substrate phosphorylation (135).

Given the generally well-tolerated nature of rapalogs, combining the first generation of mTOR inhibitors with toxicities-manageable drugs targeting signaling or metabolic pathways upstream or downstream mTORC1, still represent valuable therapeutic approaches that might reposition rapalogs in the treatment of mTOR active tumors (Figure 5).

\section{Emerging Combinations With Rapalogs}

We focus here on potentially relevant therapeutic strategies combining rapalogs with existing clinically approved agents or with new drugs under clinical evaluation (Tables 2, 3). 


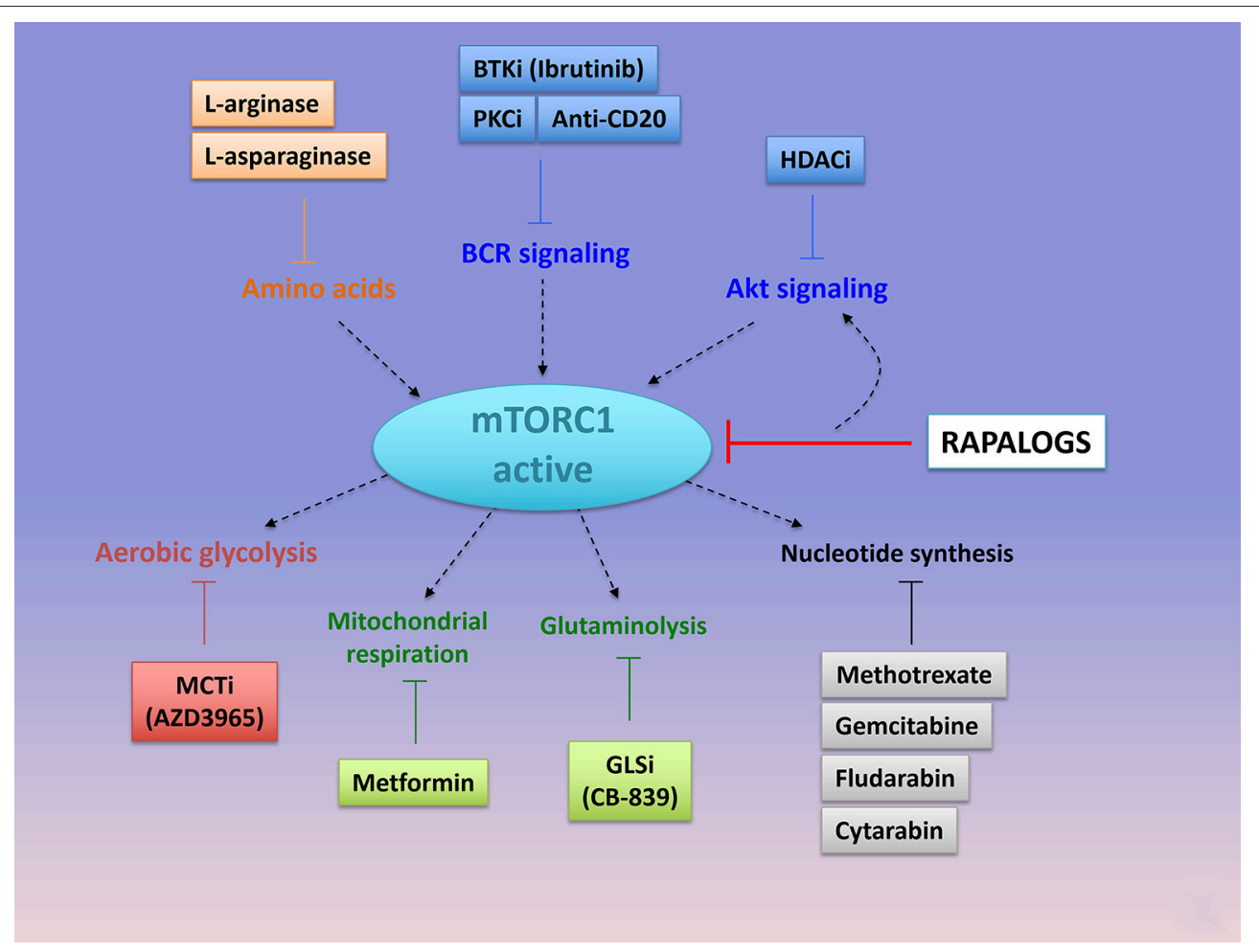

FIGURE 5 | Emerging combinations with Rapalogs. Rapalogs only partially inhibit mTORC1 signaling. Already available drugs (approved or under clinical evaluation) can be combined with rapalogs in order to induce tumor cell killing. By inhibited S6K phosphorylation, rapalogs prevent the negative feedback loop on PI3K/Akt, resulting in PI3K/Akt activation. mTORC1 can be targeted with upstream kinases involved in BCR signaling (with anti-CD20 antibody or the PKC inhibitor AEB071, or the BTK inhibitor Ibrutinib) or in Akt signaling (with HDAC inhibitors, panobinostat or vorostinat). Hydrolysis of amino acids that are required for mTORC1 activation, such as arginine (with L-arginase), or glutamine (L-asparaginase), can further abolish mTORC1 signaling and induce cell death when combined with rapalogs. mTORC1-dependent regulation of metabolism is essential to induce an anabolic program promoting cell growth. Combined Rapalogs with inhibitor of glycolysis (MCT1 inhibitor, AZD3965), or mitochondrial complex I activity (Metformin) or gutaminolysis (GLS inhibitor, CB-839) or nucleotide synthesis (Methotrexate or Gemcitabine or Fludarabine or cytarabin), might improve patient's response. Importantly, the choice of the anti-metabolic strategy depends on the metabolic status of the tumor cells. PKC, Protein Kinase C; BTK, Bruton's Tyrosine Kinase; HDAC, histone deacetylase; MCT, Monocarboxylate Transporter.

\section{Combining Rapalogs With Anti-CD20-Based Therapies}

Rapalogs were evaluated in combination with cytotoxic drugs inhibiting kinases upstream of mTORC1 to prevent rapalogsinduced reactivation of survival pathways and to promote tumor cell killing. For instance, MCL, DLBCL, and FL are currently treated with Rituximab-based chemotherapies such as R-CHOP. In vitro, Rituximab directly impact on cell viability of human CD20-expressing $\mathrm{NH}$ B-cell lymphoma cell lines by reducing (i) the expression of anti-apoptotic proteins $\mathrm{Bcl}-\mathrm{x}$, Bcl-2, XIAP, and Mcl-1 (138-140) and (ii) activity of kinases involved in BCR signaling (Lyn, Syk, Akt, Erk) $(109,141)$. In vitro, Everolimus sensitizes human GCB- and ABC-DLBCL cell lines to Rituximab-induced apoptosis by $10-20 \%$ (122, 130). Moreover, addition of Rituximab to Everolimus treatment prevents the reactivation of Akt at multi phosphorylation sites observed in Everolimus-treated cells. Consistently, combined Everolimus and Rituximab therapy is strikingly more efficient in reducing in vivo growth of human GCB-DLBCL cell lines xenografts in immunocompromised mice, than each treatment alone (130). This suggests that rapalogs can be used as an adjuvant to increase the cytotoxic effect of Rituximab, and thus provides a preclinical rationale for combining rapalogs and Rituximab clinically. Refractory/relapsed MCL treated with Rituximab as a single-agent demonstrated a ORR range from 27 to $37 \%$ (142-144). Phase II trials combining a rapalog and Rituximab in refractory/relapsed MCL (136) and DLBCL (137) are summarized in Table 2. At least for refractory/relapsed MCL, the responsiveness of this combination is higher (ORR 58 and CR 13\%) than Rituximab alone or rapalog alone (Table 1), which warrants further investigations in randomized phase 3 trials, against Everolimus or Rituximab alone.

Rituximab is usually administered in combination with a chemotherapeutic regimen, mainly anthracyclines (Hydroxydaunorubicin), alkylating agents (cyclophosphamide or bendamustine) and/or anti-microtubule alkaloids (vincristine, also named oncovin). In vitro, a synergistically induction of apoptosis was observed in cultured human MCL cell lines in the presence of chemotherapeutic agents (doxorubicine or vincristine or paclitaxel) and Everolimus (121). A phase I study has evaluated the feasibility of Everolimus plus R-CHOP for 
TABLE 2 | Phase I/II and phase II studies (ongoing or published) evaluating the effect of rapalogs in combination with anti-CD20 or anti-CD20-based therapies.

\begin{tabular}{|c|c|c|c|c|c|c|c|c|c|c|}
\hline \multirow[t]{2}{*}{ Disease } & \multicolumn{3}{|c|}{ Therapeutic regimen } & \multirow{2}{*}{$\begin{array}{c}\text { Trial } \\
\text { phase }\end{array}$} & \multirow{2}{*}{$\begin{array}{l}\text { Nbe of } \\
\text { patients in } \\
\text { the cohort }\end{array}$} & \multirow[t]{2}{*}{ ORR (\%) } & \multirow[t]{2}{*}{ CR (\%) } & \multirow[t]{2}{*}{ DR (months) } & \multirow{2}{*}{$\begin{array}{l}\text { State of the } \\
\text { study }\end{array}$} & \multirow[t]{2}{*}{ Reference } \\
\hline & Rapalog & anti-CD20 & $\begin{array}{l}\text { chemotherapeutic } \\
\text { agents }\end{array}$ & & & & & & & \\
\hline $\begin{array}{l}\text { MCL, } \\
\text { CLL/SLL, } \\
\text { DLBCL, } \\
\text { Hodgkin's } \\
\text { disease }\end{array}$ & Everolimus & Rituximab & none & $\|$ & 49 & - & - & - & active & NCT01665768 \\
\hline DLBCL & Temsirolimus & Rituximab & DHAP & $\|$ & 88 & - & - & - & active & NCT01653067 \\
\hline
\end{tabular}

MCL, Mantle Cell Lymphoma; DLBCL, Diffuse Large B Cell Lymphoma; FL, Follicular Lymphoma; CLL, Chronic Lymphocytic Leukemia; SLL, Small Lymphocytic Lymphoma; DHAP, Dexamethasone, High dose Ara-C and Platinol (cisplatin); ORR, overall response rate; $C R$, complete response; $D R$, duration response.

TABLE 3 | Anti-metabolic agents that can be combined with rapalogs to improve cytotoxic responses.

\begin{tabular}{|c|c|c|c|}
\hline Drug & Target & Status of the drug & Current indications \\
\hline \multicolumn{4}{|l|}{ NUCLEOTIDE METABOLISM } \\
\hline Gemcitabine & Ribonucleotide reductase & Approved & $\begin{array}{l}\text { Solid cancers (pancreatic, colon, lung) and NH B-cell } \\
\text { lymphomas }\end{array}$ \\
\hline Fludarabine & DNA synthesis & Approved & CLL, NH B-cell lymphomas \\
\hline Cytarabin & DNA synthesis & Approved & AML, ALL, CLL, CML, and NH lymphomas \\
\hline Metothrexate & Dihydroxyfolate reductase (DHFR) & Approved & Solid cancers (lung, breast, bladder, placenta), ALL \\
\hline $\begin{array}{l}\text { E-Coli-asparaginase Erwinase L-asparaginase, } \\
\text { PEG-asparaginase }\end{array}$ & asparagine and glutamine & Approved & $\begin{array}{l}\text { pediatric ALL Currently evaluated in adult leukemias, } \\
\text { lymphomas and solid cancers }\end{array}$ \\
\hline L-arginase & arginine & $\begin{array}{l}\text { under clinical } \\
\text { evaluation }\end{array}$ & $\begin{array}{l}\text { Currently evaluated in pediatric ALL and AML, adult } \\
\text { leukemia, Iymphomas and solid cancers (kidney, liver) }\end{array}$ \\
\hline CB-839 & Glutaminase & $\begin{array}{l}\text { under clinical } \\
\text { evaluation }\end{array}$ & $\begin{array}{l}\text { Current evaluation in ALL, AML, NH lymphomas and } \\
\text { solid cancers (kidney, lung, skin, breast, colon) }\end{array}$ \\
\hline
\end{tabular}

NH B-cell lymphomas, Non-Hodgkin's B-cell lymphomas; CLL, Chronic Lymphocytic Leukemias; AML, Acute Myeloid Leukemia; ALL, Acute Lymphoblastic Leukemias; CML, Chronic Myeloid Leukemias.

new, untreated DLBCL. This therapeutic regimen did not show dose-limiting toxicities and demonstrated $96 \%$ of CR in a cohort of 24 evaluable patients (145). Ongoing phase I/II or phase II trials combining rapalogs with other anti-CD20-based therapies for the treatment of refractory/relapsed $\mathrm{NH}$ B-cell lymphomas are reported in Table 2 .

\section{Combining Rapalogs With Specific Inhibitors of Upstream Kinases: The Bruton's Tyrosine Kinase Inhibitor (Ibrutinib) or the PKC Inhibitor (AEB071)}

The Bruton's tyrosine kinase (BTK) is required to transmit signals from the BCR to downstream kinases including PKC and thus integrates BCR and mTORC1 pathways in MCL, ABCDLCL and CLL diseases. Consequently, combining mTOR and BTK inhibitions might collapse mTORC1 upstream signaling and mTORC1 activity. When combined with Everolimus or ATP-competitive inhibitors, the Bruton's tyrosine kinase (BTK) inhibitor (Ibrutinib) induces a synergistic effect on cell death in in vitro cultures of human ABC-DLBCL cell lines $(146,147)$. Although, this co-treatment holds a potential as promising therapeutic strategy, trials evaluating ibrutinib plus a rapalog are not reported so far. Interestingly, GCB-DLBCL are not sensitive to Ibrutinib and mTOR inhibitors.

We can also mention that a therapeutic strategy targeting PKC (with the PKC inhibitor AEB071) and mTORC1 (Everolimus), in 
CD79 mutant- or ABC-DLCBL is being investigated in a phase 1 trial (NCT01854606).

\section{Combination of Rapalogs With the Histone Deacetylase (HDAC) Inhibitors}

The FDA-approved HDAC inhibitors, panobinostat (LBH589) and vorostinat have been shown to prevent Akt signaling through mTORC2 in several cancer cell lines including DLBCL (148). As expected, DLBCL cell lines co-treated with rapamycin and the panobinostat (LBH589), display a synergistically inhibited phosphorylation of p70S6K and 4E-BP1 accompanied by an impaired cell survival (148). Temsirolimus or Everolimus also synergizes with vorostinat, in the treatment of MCL cell lines $(121,149)$. A phase I trial confirmed the effectiveness of this combination in a variety of refractory/relapse lymphomas, but with a cost of significant toxicity (150). A phase 2 study evaluating Everolimus and LBH589 in the treatment of refractory/relapsed DLBCL was aborted for toxicity reasons (NCT00978432).

\section{Combining Rapalogs With Anti-metabolic Agents}

The activation of both mTORC1 and mTORC2 pathways enhances cell metabolism (nucleotide, amino acid, and energetic metabolism), by regulating expression and/or activity of numerous metabolic enzymes to enable cell survival and growth. In turn, consequences of high metabolic activities allow persistent mTORC1 signaling. Since rapalogs are not able to fully abolish the function of certain mTORC1 substrates, there is a "leak" in the remaining metabolic fluxes, that can be directly targeted in order to further decrease the metabolic reprogramming regulated by $\mathrm{mTOR}$ and to prevent mTOR reactivation. Interestingly, targeting cell metabolism is of high clinical interest since many anti-metabolic drugs are already approved in the treatment of several types of cancers including B-cell malignancies or in the treatment of metabolic diseases and thus they can be easily evaluated in combination with rapalogs. Anti-metabolic drugs refer to any drug that might directly or indirectly target metabolic pathways.

\section{Targeting nucleotide metabolism}

Among the first effective chemotherapeutic agents identified are anti-metabolic drugs targeting nucleotides metabolism. By incorporating into DNA, RNA, or by inhibiting enzymes involved in nucleotide synthesis, this class of anti-metabolic agents slows purine and pyrimidine synthesis and DNA replication, thereby inducing cytotoxicity during the $\mathrm{S}$ phase of the cell cycle. Gemcitabine, a pyrimidine antagonist, inhibits DNA and RNA synthesis and causes cell cycle arrest. This drug is effective in the treatment of DLBCL when introduced in the therapeutic regimen R-GEMOX (Rituximab, Gemcitabine, Oxaliplatine). Fludarabine is a purine antagonist used in combination with Rituxmab and cyclophosphamide (R-FC) in the treatment of CLL. Cytarabin is a pyrimidine nucleoside analog routinely used in the treatment of AML. A phase 2 study combining Temsirolimus, Rituximab and high doses of cytarabin-based chemotherapy (DHAP), is currently ongoing in refractory/relapsed DLBCL [NCT01653067, (151)]. Not only purine and pyrimidine but also folic acid is necessary for the production of nucleotides. Methotrexate binds and inactivates an enzyme of folic acid metabolism, the dihydroxyfolate reductase (DHFR). This causes a decrease in DNA and RNA synthesis. Methotrexane is clinically used to prevent central nervous system relapse in patients with DLBCL. The combination of mTOR inhibitors and methotrexane were tested in acute lymphoblastic leukemia where it was synergistically effective (152). Administration of Temsirolimus and methotrexane leads to an increase OS and durable remission in immunocompetent mice xenografted with human AML patient samples (152).

\section{Targeting energetic pathways}

mTORC1 stimulates flux through different metabolic pathways including glycolysis, PPP, and OxPhos. Targeting mTORC1 and its downstream metabolic network might impair cellular energy production and tumor cell viability. Taking into consideration the existence of OxPhos tumor clusters (within a same tumor entity) and the OxPhos reliance of therapy-resistant tumors (41, 153), combining rapalogs with inhibitors of oxidative metabolism might enhance patient responses. The biguanide metformin is the best-characterized anti-metabolic agent that has found an application in the treatment of patients with type II diabetes (154). Metformin inhibits mitochondrial complex I activity, thereby decreasing cellular respiration, mitochondrial ATP production and increasing glucose uptake as a compensatory mechanism $(155,156)$. This last two decades, preclinical studies demonstrated that Metformin holds effective antiproliferative activities in numerous human cancer cell lines, including NH B-cell lymphomas, thus repositioning Metformin in cancer prevention and treatment (157-161). Mechanistically, Metformin-induced energy depletion blocks mTORC1 activity in a AMPK-dependent or -independent manner, in physiological (162) and in pathological contexts $(159,163)$ In human DLBCL and Burkitt cell lines, Metformin inhibits mTORC1 and reduces cell proliferation in an AMPK dependent manner (164). Thus, combining Temsirolimus with Metformin shows a stronger in vivo growth inhibition than each treatment alone in B lymphoma xenografts (164). Other types of kinase inhibitors converging toward mTORC1 inhibition and biguanides synergistically impair tumor growth (165). In the clinic, indirect proof-ofconcept of Metformin efficacy in DLBCL is demonstrated by a significant increase in PFS and CR of diabetic DLBCL patients on metformin compared to non-diabetic DLBCL patients (166). Phase 1 and phase 2 studies combining a rapalog and Metformin are currently ongoing in the treatment of several advanced solid cancers (NCT02048384; NCT01797523; NCT01529593), including lymphomas (NCT00659568).

Upon inhibition of glycolysis, mTORC1 sustains cell viability by reprogramming metabolism toward glutaminolysis and OxPhos metabolism. Inhibition of mTORC1 signaling decreases cellular respiration of glycolysis-independent cells. Co-targeting glycolysis and mTORC1 thus prevents metabolic escape and synergistically inhibits xenograft tumor progression (167). Although LDH-A represented a promising target for anti-cancer therapy $(168,169)$, none of the LDH-A inhibitors progressed in the clinic. Nevertheless, selective inhibition of the lactate transporter 1 (MCT1) with AZD3965 induces a negative feedback 
loop on the glycolytic rate and represents an alternative approach to target MCT4-defective glycolytic tumors (170). AZD3965 is currently under clinical evaluation in advanced solid cancers, in DLBCL and in Burkitt lymphomas (NCT01791595).

\section{Targeting amino acids}

Targeting extracellular sources of amino acids that are indirectly sensed by mTORC1 to regulate its activity represent another promising therapeutic option that might be used in combination with rapalogs to further prevent mTORC1 functions. So far, the key amino acids involved in mTORC1 regulation are arginase, leucine and glutamine. Glutamine uptake is required to uptake leucine and to promote leucine-dependent stimulation of mTORC1 at the lysosome. The L-asparaginase (E-Coli, Erwinase and other derivatives) hydrolyses extracellular asparagine and glutamine and prevents mTORC1 activation (63). L-asparaginase is highly effective in children undergoing induction therapy for acute lymphoblastic leukemias (ALL) and thus became a standard treatment for this childhood ALL. Severe adverse events associated with L-asparaginase reduced its clinical utilization in adults. Nevertheless, phase 2 studies evaluating L-asparaginase are currently ongoing for the treatment of multiple adult $\mathrm{NH}$ B-cell lymphomas and adult leukemias (NCT00018954 and NCT00002471). In vitro co-targeting of extracellular glutamine/asparagine and $\mathrm{mTORC} 1$ has, at least, additive effect, resulting in a stronger reduction of ALL cell lines viability (152). A phase 1 study is ongoing to evaluate the feasibility of combining Everolimus with chemotherapeutic agents including PEG(pegylated)-asparaginase in patients with ALL (NCT01523977). Similarly, L-arginase hydrolyses arginine and might further prevent mTORC1 activation in combination with rapalogs. It is worth mentioning that recombinant human arginase is under clinical evaluation in solid cancers (hepatocellular carcinomas, NCT00988195; liver cancers, NCT NCT00988195; melanoma and prostate adenocarcinomas, NCT02295101), in pediatric solid tumors, AML and ALL (NCT03455140) and in adult refractory/relapsed AML (NCT02899286).

Upon resistance to mTOR inhibition, glycolytic tumors upregulate the glutaminase (GLS) and switch to glutamine metabolism (171). The GLS inhibitor, CB-839 prevents the conversion of glutamine into glutamate and thus restricts carbonderived glutamine sources required for in vitro TCA cycle anaplerosis and cell proliferation $(19,172-174)$. Inhibition of GLS activity overcomes resistance to mTOR inhibition (171) and provides a rational to target mTOR and GLS in metabolically flexible tumors. More generally, tumor cells overexpressing MYC are highly sensitive to GLS inhibition as they mainly rely on glutamine oxidation to replenish the TCA cycle, even in hypoxic conditions $(19,174)$. This suggests that patients with treatmentresistant MYC-translocated NH B-cell lymphomas might be susceptible to a combination of CB-839 and mTOR inhibitor. CB-839 is currently tested in a phase 1 trial in advanced and/or treatment refractory hematologic malignancies including $\mathrm{NH}$ lymphomas (NCT02071888) and is evaluating in combination with Everolimus in a phase 2 study in clear cell renal cell carcinomas (NCT 03163667).
It is important to note that therapeutic strategies combining rapalogs with anti-metabolic drugs hold potential as effective therapies only if we can better characterize the tumor metabolic state to address the best-adequate combination.

\section{OUTLOOK AND CONCLUSIONS}

Targeting the metabolic control of tumor cells and more specifically of malignant $\mathrm{B}$-cells hold potential as a promising anti-cancer strategy. As we discussed in this review, the first generation of mTORC1 inhibitors were effective in vitro, but the benefits provided to patients were often limited and quite disappointing. One of the reasons concerns the preclinical studies evaluating the impact of rapalogs on the survival of human transformed cells lines in vitro. All cell lines analyzed display increased mTORC1 signaling and show a reduction of cell proliferation upon mTORC1 inhibition. On the opposite, only a fraction of primary human $\mathrm{NH}$ B-cell lymphomas exhibit active mTORC1 signaling and are sensitive to rapalogs. It is likely that in vitro culture conditions, that provide nutrients in excess and stimulate the energetic and anabolic demands, select for rapid proliferating cells, glycolytic metabolism and chronic active mTORC1 signaling. However, in vivo, the intrinsic metabolic heterogeneity and the tumor microenvironment massively influence nutrient availability, which in turn modulates mTORC1 activation. Such biological factors should be taken into consideration when analyzing $\mathrm{MTORC} 1$ signaling and its inhibition in cancer. Thus, it is unlikely that in vitro culture of human transformed cell lines is relevant to the study of signaling pathways depending on nutrients to regulate cell metabolism and growth, as it might overestimate the effect induced by inhibition of these pathways. Moreover, the lack of robust pre-clinical models, that recapitulate the complex aspects of molecular heterogeneity of each human NH B-cell lymphomas, participates to the weakness of preclinical studies that evaluated in vivo efficacy of rapalogs in those malignances.

The absence of cytotoxic effect of rapalogs is also a main drawback. However, in rare cases, complete responses were obtained in patients with refractory/relapsed MCL, DLBCL, or FL, suggesting that some B lymphomas might be extremely sensitive to rapalogs probably because they display heavily active mTORC1 signaling. Identification of activating mutations in mTORC1 or of biomarkers of mTORC1 activity status will be helpful to predict the responsiveness of patients to rapalogs alone or in combination with other targeted therapies. Indeed, key information on rapalogs sensitivity can be collected from genetic investigations of tumor patients prior to mTOR-targeted therapies. Interestingly, tumors such as metastatic bladder cancers harboring the loss of function mutations in TSC1, are associated with Everolimus sensitivity in patients (175). In a phase 1 study, one patient with metastatic urothelial carcinoma refractory to current therapies presented a complete and durable (14 months) response to Everolimus and pazopanib treatment. Prior therapy, whole-exome sequencing of its extremely sensitive tumor revealed two activating mutations in mTOR (176). Such studies reinforce the idea that personalized medicine 
should be further considered in order to select patients who might respond to specific therapies. Importantly, 33 different mutations in mTOR components were recently reported in a variety of solid cancers (177). All these mutations confer hyperactivation of mTOR signaling. Although genetic alterations upstream of mTORC1 have been reported in different class of NH B-cell lymphomas, it might only represent a small proportion of mTOR active lymphomas. Obviously, the lack of a standardized approach to stratify patients with mTOR active tumors contributes in part to the limited clinical success of rapalogs. Since the diagnosis of $\mathrm{NH}$ B-cell lymphomas mainly relies on IHC staining of B cell specific markers in paraffin-embedded tumor sections (except for CLL that are diagnosed from blood samples of patients), determination of active or inactive mTORC1 signaling by IHC would be optimal. mTORC1 target phosphorylated-S6 was detected in $62 \%$ of newly diagnosed DLBCL (86). However, ORR is seen in only $30 \%$ of refractory/relapsed DLBCL (Table 1), raising two main questions far away from being solved. Firstly, is the level of mTORC1 activity different from the diagnosis to the relapsed after the first line therapies? Secondly, can we predict the response of $\mathrm{NH}$ B-cell lymphoma patients to rapalog by detecting mTOR targets in tumors? Different approaches (WB, IF, and IHC) to identify molecules related to mTOR activity such as

\section{REFERENCES}

1. Cummings AL, Garon EB. The ascent of immune checkpoint inhibitors: is the understudy ready for a leading role? Cancer Biol Med. (2017) 14:341-7. doi: 10.20892/j.issn.2095-3941.2017.0090

2. Pollizzi KN, Powell JD. Regulation of $\mathrm{T}$ cells by mTOR: the known knowns and the known unknowns. Trends Immunol. (2015) 36:13-20. doi: 10.1016/j.it.2014.11.005

3. Iwata TN, Ramírez JA, Tsang M, Park H, Margineantu DH, Hockenbery DM, et al. Conditional disruption of raptor reveals an essential role for mTORC1 in B cell development, survival, and metabolism. J Immunol. (2016) 197:2250-60. doi: 10.4049/jimmunol.16 00492

4. Ersching J, Efeyan A, Mesin L, Jacobsen JT, Pasqual G, Grabiner $\mathrm{BC}$, et al. Germinal center selection and affinity maturation require dynamic regulation of mTORC1 kinase. Immunity (2017) 46:1045-58 e6. doi: 10.1016/j.immuni.2017.06.005

5. A clinical evaluation of the International Lymphoma Study Group classification of non-Hodgkin's lymphoma. The Non-Hodgkin's Lymphoma Classification Project. Blood (1997) 89:3909-18.

6. Smith MR. Rituximab (monoclonal anti-CD20 antibody): mechanisms of action and resistance. Oncogene (2003) 22:7359-68. doi: 10.1038/sj.onc.1206939

7. Parks SK, Chiche J, Pouyssegur J. Disrupting proton dynamics and energy metabolism for cancer therapy. Nat Rev Cancer (2013) 13:611-23. doi: $10.1038 / \mathrm{nrc} 3579$

8. Carracedo A, Cantley LC, Pandolfi PP. Cancer metabolism: fatty acid oxidation in the limelight. Nat Rev Cancer (2013) 13:227-32. doi: $10.1038 / \mathrm{nrc} 3483$

9. Bhutia YD, Ganapathy V. Glutamine transporters in mammalian cells and their functions in physiology and cancer. Biochim Biophys Acta (2016) 1863:2531-9. doi: 10.1016/j.bbamcr.2015.12.017

10. Timmerman LA, Holton T, Yuneva M, Louie RJ, Padró M, Daemen A, et al. Glutamine sensitivity analysis identifies the $\mathrm{xCT}$ antiporter as a common triple-negative breast tumor therapeutic target. Cancer Cell (2013) 24:45065. doi: 10.1016/j.ccr.2013.08.020
mTOR, p-mTOR, and its targets, p-p70S6K, p-S6Rb, and p4E-BP1 were compared in renal cell carcinoma biopsies using different approaches in order to find the best strategy to identify mTORC1 active tumors. It appears that only phosphorylatedS6K is a robust marker for detection of mTOR activity in tumor samples by at least two techniques including IHC, while the others molecules failed to be detected by IHC (178). Finally, the lack of robust and easily accessible biomarkers to evaluate the metabolic state of a given patient and, if possible, the heterogeneity of the metabolic status within the same tumor entity still represents a major block in the field. However, we can be confident that this missing gap will be documented in a near future.

\section{AUTHOR CONTRIBUTIONS}

All authors listed have made a substantial, direct and intellectual contribution to the work, and approved it for publication.

\section{FUNDING}

This work has been supported by the Fondation ARC pour la Recherche sur le Cancer (PGA1 RC20170205463) and the Cancéropôle PACA.

11. Davidson SM, Papagiannakopoulos T, Olenchock BA, Heyman JE, Keibler MA, Luengo A, et al. Environment impacts the metabolic dependencies of ras-driven non-small cell lung cancer. Cell Metab. (2016) 23:517-28. doi: 10.1016/j.cmet.2016.01.007

12. Sellers K, Fox MP, Bousamra M, Slone SP, Higashi RM, Miller DM, et al. Pyruvate carboxylase is critical for non-small-cell lung cancer proliferation. J Clin Invest. (2015) 125:687-98. doi: 10.1172/JCI72873

13. Marin-Valencia I, Yang C, Mashimo T, Cho S, Baek H, Yang XL, et al. Analysis of tumor metabolism reveals mitochondrial glucose oxidation in genetically diverse human glioblastomas in the mouse brain in vivo. Cell Metab. (2012) 15:827-37. doi: 10.1016/j.cmet.2012.10.010

14. Tardito S, Oudin A, Ahmed SU, Fack F, Keunen O, Zheng L, et al. Glutamine synthetase activity fuels nucleotide biosynthesis and supports growth of glutamine-restricted glioblastoma. Nat Cell Biol. (2015) 17:155668. doi: $10.1038 /$ ncb3272

15. Commisso C, Davidson SM, Soydaner-Azeloglu RG, Parker SJ, Kamphorst JJ, Hackett S, et al. Macropinocytosis of protein is an amino acid supply route in Ras-transformed cells. Nature (2013) 497:633-7. doi: 10.1038/nature 12138

16. Kamphorst JJ, Nofal M, Commisso C, Hackett SR, Lu W, Grabocka E, et al. Human pancreatic cancer tumors are nutrient poor and tumor cells actively scavenge extracellular protein. Cancer Res. (2015) 75:544-53. doi: 10.1158/0008-5472.CAN-14-2211

17. Davidson SM, Jonas O, Keibler MA, Hou HW, Luengo A, Mayers JR, et al. Direct evidence for cancer-cell-autonomous extracellular protein catabolism in pancreatic tumors. Nat Med. (2016) 23:235-41. doi: 10.1038/nm.4256

18. Venneti S, Dunphy MP, Zhang H, Pitter KL, Zanzonico P, Campos $\mathrm{C}$, et al. Glutamine-based PET imaging facilitates enhanced metabolic evaluation of gliomas in vivo. Sci Transl Med. (2015) 7:274ra17. doi: 10.1126/scitranslmed.aaa1009

19. Le A, Lane AN, Hamaker M, Bose S, Gouw A, Barbi J, et al. Glucose-independent glutamine metabolism via TCA cycling for proliferation and survival in B cells. Cell Metab. (2012) 15:110-21. doi: 10.1016/j.cmet.2011.12.009

20. DeBerardinis RJ, Chandel NS. Fundamentals of cancer metabolism. Sci Adv. (2016) 2:e1600200. doi: 10.1126/sciadv.1600200 
21. Chang CH, Qiu J, O'Sullivan D, Buck MD, Noguchi T, Curtis JD, et al. Metabolic competition in the tumor microenvironment is a driver of cancer progression. Cell (2015) 162:1229-41. doi: 10.1016/j.cell.2015.08.016

22. Chicco AJ, Le CH, Gnaiger E, Dreyer HC, Muyskens JB, D’Alessandro A, et al. Adaptive remodeling of skeletal muscle energy metabolism in highaltitude hypoxia: lessons from altitudeomics. J Biol Chem. (2018) 293:665971. doi: 10.1074/jbc.RA117.000470

23. Brahimi-Horn MC, Chiche J, Pouyssegur J. Hypoxia signalling controls metabolic demand. Curr Opin Cell Biol. (2007) 19:223-9. doi: 10.1016/j.ceb.2007.02.003

24. Warburg O. On respiratory impairment in cancer cells. Science (1956) 124:269-70.

25. Koppenol WH, Bounds PL, Dang CV. Otto Warburg's contributions to current concepts of cancer metabolism. Nat Rev Cancer (2011) 11:325-37. doi: 10.1038/nrc3038

26. Vander Heiden MG, Cantley LC, Thompson CB. Understanding the warburg effect: the metabolic requirements of cell proliferation. Science (2009) 324:1029-33. doi: 10.1126/science.1160809

27. Chang CH, Curtis JD, Maggi LB, Faubert B, Villarino AV, O'Sullivan D, et al. Posttranscriptional control of $\mathrm{T}$ cell effector function by aerobic glycolysis. Cell (2013) 153:1239-51. doi: 10.1016/j.cell.2013.05.016

28. Geltink RIK, Kyle RL, Pearce EL. Unraveling the complex interplay between T cell metabolism and function. Annu Rev Immunol. (2018) 36:461-88. doi: 10.1146/annurev-immunol-042617-053019

29. Shi LZ, Wang R, Huang G, Vogel P, Neale G, Green DR, et al. HIFlalphadependent glycolytic pathway orchestrates a metabolic checkpoint for the differentiation of TH17 and Treg cells. J Exp Med. (2011) 208:1367-76. doi: $10.1084 /$ jem. 20110278

30. van der Windt GJ, Pearce EL. Metabolic switching and fuel choice during Tcell differentiation and memory development. Immunol Rev. (2012) 249:2742. doi: 10.1111/j.1600-065X.2012.01150.x

31. Sonveaux P, Végran F, Schroeder T, Wergin MC, Verrax J, Rabbani ZN, et al. Targeting lactate-fueled respiration selectively kills hypoxic tumor cells in mice. J Clin Invest. (2008) 118:3930-42. doi: 10.1172/JCI36843

32. Brand A, Singer K, Koehl GE, Kolitzus M, Schoenhammer G, Thiel A, et al. LDHA-associated lactic acid production blunts tumor immunosurveillance by $\mathrm{T}$ and NK Cells. Cell Metab. (2016) 24:657-71. doi: $10.1016 /$ j.cmet.2016.08.011

33. DeBerardinis RJ, Lum JJ, Hatzivassiliou G, Thompson CB. The biology of cancer: metabolic reprogramming fuels cell growth and proliferation. Cell Metab. (2008) 7:11-20. doi: 10.1016/j.cmet.2007.10.002

34. Dang L, White DW, Gross S, Bennett BD, Bittinger MA, Driggers EM, et al. Cancer-associated IDH1 mutations produce 2-hydroxyglutarate. Nature (2009) 462:739-44. doi: 10.1038/nature08617

35. Weinberg F, Hamanaka R, Wheaton WW, Weinberg S, Joseph J, Lopez $\mathrm{M}$, et al. Mitochondrial metabolism and ROS generation are essential for Kras-mediated tumorigenicity. Proc Natl Acad Sci USA. (2010) 107:8788-93. doi: $10.1073 /$ pnas. 1003428107

36. Maher EA, Marin-Valencia I, Bachoo RM, Mashimo T, Raisanen J, Hatanpaa $\mathrm{KJ}$, et al. Metabolism of [U-13 C]glucose in human brain tumors in vivo. NMR Biomed. (2012) 25:1234-44. doi: 10.1002/nbm.2794

37. Faubert B, Li KY, Cai L, Hensley CT, Kim J, Zacharias LG, et al. Lactate metabolism in human lung tumors. Cell (2017) 171:358-71 e9. doi: 10.1016/j.cell.2017.09.019

38. Monti S, Savage KJ, Kutok JL, Feuerhake F, Kurtin P, Mihm M, et al. Molecular profiling of diffuse large B-cell lymphoma identifies robust subtypes including one characterized by host inflammatory response. Blood (2005) 105:1851-61. doi: 10.1182/blood-2004-07-2947

39. Caro P, Kishan AU, Norberg E, Stanley IA, Chapuy B, Ficarro SB, et al. Metabolic signatures uncover distinct targets in molecular subsets of diffuse large B cell lymphoma. Cancer Cell (2012) 22:547-60. doi: 10.1016/j.ccr.2012.08.014

40. Vazquez F, Lim JH, Chim H, Bhalla K, Girnun G, Pierce K, et al. PGC1alpha expression defines a subset of human melanoma tumors with increased mitochondrial capacity and resistance to oxidative stress. Cancer Cell (2013) 23:287-301. doi: 10.1016/j.ccr.2012.11.020

41. Viale A, Pettazzoni P, Lyssiotis CA, Ying H, Sánchez N, Marchesini $\mathrm{M}$, et al. Oncogene ablation-resistant pancreatic cancer cells depend on mitochondrial function. Nature (2014) 514:628-32. doi: 10.1038/nature13611

42. Hensley CT, Faubert B, Yuan Q, Lev-Cohain N, Jin E, Kim J, et al. Metabolic heterogeneity in human lung tumors. Cell (2016) 164:681-94. doi: 10.1016/j.cell.2015.12.034

43. Yang H, Rudge DG, Koos JD, Vaidialingam B, Yang HJ, Pavletich NP. mTOR kinase structure, mechanism and regulation. Nature (2013) 497:217-23. doi: 10.1038/nature 12122

44. Liu P, Gan W, Chin YR, Ogura K, Guo J, Zhang J, et al. PtdIns(3,4,5)P3Dependent activation of the mTORC2 kinase complex. Cancer Discov. (2015) 5:1194-209. doi: 10.1158/2159-8290.CD-15-0460

45. Jacinto E, Loewith R, Schmidt A, Lin S, Rüegg MA, Hall A, et al. Mammalian TOR complex 2 controls the actin cytoskeleton and is rapamycin insensitive. Nat Cell Biol. (2004) 6:1122-8. doi: 10.1038/ncb1183

46. Sarbassov DD, Ali SM, Kim DH, Guertin DA, Latek RR, Erdjument-Bromage $\mathrm{H}$, et al. Rictor, a novel binding partner of mTOR, defines a rapamycininsensitive and raptor-independent pathway that regulates the cytoskeleton. Curr Biol. (2004) 14:1296-302. doi: 10.1016/j.cub.2004.06.054

47. Sarbassov DD, Guertin DA, Ali SM, Sabatini DM. Phosphorylation and regulation of Akt/PKB by the rictor-mTOR complex. Science (2005) 307:1098-101. doi: 10.1126/science.1106148

48. Lee DF, Kuo HP, Chen CT, Hsu JM, Chou CK, Wei Y, et al. IKK beta suppression of TSC1 links inflammation and tumor angiogenesis via the mTOR pathway. Cell (2007) 130:440-55. doi: 10.1016/j.cell.2007.05.058

49. Ma L, Chen Z, Erdjument-Bromage H, Tempst P, Pandolfi PP. Phosphorylation and functional inactivation of TSC2 by Erk implications for tuberous sclerosis and cancer pathogenesis. Cell (2005) 121:179-93. doi: 10.1016/j.cell.2005.02.031

50. Roux PP, Ballif BA, Anjum R, Gygi SP, Blenis J. Tumor-promoting phorbol esters and activated Ras inactivate the tuberous sclerosis tumor suppressor complex via p90 ribosomal S6 kinase. Proc Natl Acad Sci USA. (2004) 101:13489-94. doi: 10.1073/pnas.0405659101

51. Inoki $\mathrm{K}$, Zhu $\mathrm{T}$, Guan $\mathrm{KL}$. TSC2 mediates cellular energy response to control cell growth and survival. Cell (2003) 115:577-90. doi: 10.1016/S0092-8674(03)00929-2

52. Brugarolas J, Lei K, Hurley RL, Manning BD, Reiling JH, Hafen E, et al. Regulation of mTOR function in response to hypoxia by REDD1 and the TSC1/TSC2 tumor suppressor complex. Genes Dev. (2004) 18:2893-904. doi: 10.1101/gad.1256804

53. Gwinn DM, Shackelford DB, Egan DF, Mihaylova MM, Mery A, Vasquez DS, et al. AMPK phosphorylation of raptor mediates a metabolic checkpoint. Mol Cell (2008) 30:214-26. doi: 10.1016/j.molcel.2008. 03.003

54. Lee MN, Ha SH, Kim J, Koh A, Lee CS, Kim JH, et al. Glycolytic flux signals to mTOR through glyceraldehyde-3-phosphate dehydrogenasemediated regulation of Rheb. Mol Cell Biol. (2009) 29:3991-4001. doi: 10.1128/MCB.00165-09

55. Bar-Peled L, Sabatini DM. Regulation of mTORC1 by amino acids. Trends Cell Biol. (2014) 24:400-6. doi: 10.1016/j.tcb.2014.03.003

56. Saxton RA, Knockenhauer KE, Wolfson RL, Chantranupong L, Pacold ME, Wang T, et al. Structural basis for leucine sensing by the Sestrin2mTORC1 pathway. Science (2016) 351:53-8. doi: 10.1126/science.aa d2087

57. Saxton RA, Chantranupong L, Knockenhauer KE, Schwartz TU, Sabatini DM. Mechanism of arginine sensing by CASTOR1 upstream of mTORC1. Nature (2016) 536:229-33. doi: 10.1038/nature19079

58. Chantranupong L, Scaria SM, Saxton RA, Gygi MP, Shen K, Wyant GA, et al. The CASTOR proteins are arginine sensors for the mTORC1 pathway. Cell (2016) 165:153-64. doi: 10.1016/j.cell.2016.02.035

59. Kim E, Goraksha-Hicks P, Li L, Neufeld TP, Guan KL. Regulation of TORC1 by Rag GTPases in nutrient response. Nat Cell Biol. (2008) 10:935-45. doi: $10.1038 /$ ncb1753

60. Sancak Y, Peterson TR, Shaul YD, Lindquist RA, Thoreen CC, Bar-Peled L, et al. The Rag GTPases bind raptor and mediate amino acid signaling to mTORC1. Science (2008) 320:1496-501. doi: 10.1126/science.1157535

61. Durán RV, Oppliger W, Robitaille AM, Heiserich L, Skendaj R, Gottlieb E, et al. Glutaminolysis activates Rag-mTORC1 signaling. Mol Cell. (2012) 47:349-58. doi: 10.1016/j.molcel.2012.05.043 
62. Jewell JL, Kim YC, Russell RC, Yu FX, Park HW, Plouffe SW, et al. Metabolism differential regulation of mTORC1 by leucine and glutamine. Science (2015) 347:194-8. doi: 10.1126/science. 1259472

63. Willems L, Jacque N, Jacquel A, Neveux N, Maciel TT, Lambert $\mathrm{M}$, et al. Inhibiting glutamine uptake represents an attractive new strategy for treating acute myeloid leukemia. Blood (2013) 122:3521-32. doi: 10.1182/blood-2013-03-493163

64. Wang S, Tsun ZY, Wolfson RL, Shen K, Wyant GA, Plovanich ME, et al. Metabolism. Lysosomal amino acid transporter SLC38A9 signals arginine sufficiency to mTORC1. Science (2015) 347:188-94. doi: $10.1126 /$ science. 1257132

65. Milkereit R, Persaud A, Vanoaica L, Guetg A, Verrey F, Rotin D. LAPTM4b recruits the LAT1-4F2hc Leu transporter to lysosomes and promotes mTORC1 activation. Nat Commun. (2015) 6:7250. doi: $10.1038 /$ ncomms 8250

66. Ma XM, Blenis J. Molecular mechanisms of mTOR-mediated translational control. Nat Rev Mol Cell Biol. (2009) 10:307-18. doi: 10.1038/nrm2672

67. Pavlova NN, Hui S, Ghergurovich JM, Fan J, Intlekofer AM, White RM, et al. As extracellular glutamine levels decline, asparagine becomes an essential amino acid. Cell Metab. (2018) 27:428-38 e5. doi: 10.1016/j.cmet.2017.12.006

68. Peng T, Golub TR, Sabatini DM. The immunosuppressant rapamycin mimics a starvation-like signal distinct from amino acid and glucose deprivation. Mol Cell Biol. (2002) 22:5575-84. doi: 10.1128/MCB.22.15.5575-5584.2002

69. Ramanathan A, Schreiber SL. Direct control of mitochondrial function by mTOR. Proc Natl Acad Sci USA. (2009) 106:22229-32. doi: 10.1073/pnas.0912074106

70. Ben-Sahra I, Howell JJ, Asara JM, Manning BD. Stimulation of de novo pyrimidine synthesis by growth signaling through $\mathrm{mTOR}$ and S6K1. Science (2013) 339:1323-8. doi: 10.1126/science.1228792

71. Ben-Sahra I, Hoxhaj G, Ricoult SJH, Asara JM, Manning BD. mTORC1 induces purine synthesis through control of the mitochondrial tetrahydrofolate cycle. Science (2016) 351:728-33. doi: 10.1126/science.aad0489

72. Düvel K, Yecies JL, Menon S, Raman P, Lipovsky AI, Souza AL, et al. Activation of a metabolic gene regulatory network downstream of mTOR complex 1. Mol Cell (2010) 39:171-83. doi: 10.1016/j.molcel.2010.06.022

73. Cunningham JT, Rodgers JT, Arlow DH, Vazquez F, Mootha VK, Puigserver P. mTOR controls mitochondrial oxidative function through a YY1-PGC-1alpha transcriptional complex. Nature (2007) 450:736-40. doi: 10.1038/nature 06322

74. Morita M, Gravel SP, Chénard V, Sikström K, Zheng L, Alain T, et al. mTORC1 controls mitochondrial activity and biogenesis through $4 \mathrm{E}-$ BP-dependent translational regulation. Cell Metab. (2013) 18:698-711. doi: 10.1016/j.cmet.2013.10.001

75. Peterson TR, Sengupta SS, Harris TE, Carmack AE, Kang SA, Balderas E, et al. mTOR complex 1 regulates lipin 1 localization to control the SREBP pathway. Cell (2011) 146:408-20. doi: 10.1016/j.cell.2011.06.034

76. Csibi A, Lee G, Yoon SO, Tong H, Ilter D, Elia I, et al. The mTORC1/S6K1 pathway regulates glutamine metabolism through the eIF4B-dependent control of c-Myc translation. Curr Biol. (2014) 24:2274-80. doi: 10.1016/j.cub.2014.08.007

77. Csibi A, Fendt SM, Li C, Poulogiannis G, Choo AY, Chapski DJ, et al. The mTORC1 pathway stimulates glutamine metabolism and cell proliferation by repressing SIRT4. Cell (2013) 153:840-54. doi: 10.1016/j.cell.2013.04.023

78. Witzig TE, Geyer SM, Ghobrial I, Inwards DJ, Fonseca R, Kurtin P, et al. Phase II trial of single-agent temsirolimus (CCI-779) for relapsed mantle cell lymphoma. J Clin Oncol. (2005) 23:5347-56. doi: 10.1200/JCO.2005.13.466

79. Ansell SM, Inwards DJ, Rowland KM, Flynn PJ, Morton RF, Moore DF, et al. Low-dose, single-agent temsirolimus for relapsed mantle cell lymphoma: a phase 2 trial in the North Central Cancer Treatment Group. Cancer (2008) 113:508-14. doi: $10.1002 / \mathrm{cncr} .23580$

80. Hess G, Herbrecht R, Romaguera J, Verhoef G, Crump M, Gisselbrecht C, et al. Phase III study to evaluate temsirolimus compared with investigator's choice therapy for the treatment of relapsed or refractory mantle cell lymphoma. J Clin Oncol. (2009) 27:3822-9. doi: 10.1200/JCO.2008.20.7977

81. Witzig TE, Reeder CB, LaPlant BR, Gupta M, Johnston PB, Micallef IN, et al. A phase II trial of the oral mTOR inhibitor everolimus in relapsed aggressive lymphoma. Leukemia (2011) 25:341-7. doi: 10.1038/leu.2010.226
82. Renner C, Zinzani PL, Gressin R, Klingbiel D, Dietrich PY, Hitz F, et al. A multicenter phase II trial (SAKK 36/06) of single-agent everolimus (RAD001) in patients with relapsed or refractory mantle cell lymphoma. Haematologica (2012) 97:1085-91. doi: 10.3324/haematol.2011.053173

83. Smith SM, van Besien K, Karrison T, Dancey J, McLaughlin P, Younes A, et al. Temsirolimus has activity in non-mantle cell non-Hodgkin's lymphoma subtypes: The University of Chicago phase II consortium. J Clin Oncol. (2010) 28:4740-6. doi: 10.1200/JCO.2010.29.2813

84. Coiffier B, Lepage E, Briere J, Herbrecht R, Tilly H, Bouabdallah R, et al. CHOP chemotherapy plus rituximab compared with $\mathrm{CHOP}$ alone in elderly patients with diffuse large-B-cell lymphoma. N Engl J Med. (2002) 346:235-42. doi: 10.1056/NEJMoa011795

85. Alizadeh AA, Eisen MB, Davis RE, Ma C, Lossos IS, Rosenwald A, et al. Distinct types of diffuse large B-cell lymphoma identified by gene expression profiling. Nature (2000) 403:503-11. doi: 10.1038/35000501

86. Sebestyen A, Sticz TB, Mark A, Hajdu M, Timár B, Nemes K et al. Activity and complexes of mTOR in diffuse large B-cell lymphomas-a tissue microarray study. Modern Pathol. (2012) 25:1623-8. doi: 10.1038/modpathol.2012.141

87. Reddy A, Zhang J, Davis NS, Moffitt AB, Love CL, Waldrop A, et al. Genetic and functional drivers of diffuse large B cell lymphoma. Cell (2017) 171:481-94 e15. doi: 10.1016/j.cell.2017.09.027

88. Mavrakis KJ, Zhu H, Silva RL, Mills JR, Teruya-Feldstein J, Lowe SW, et al. Tumorigenic activity and therapeutic inhibition of Rheb GTPase. Genes Dev. (2008) 22:2178-88. doi: 10.1101/gad.1690808

89. Sakai A, Thieblemont C, Wellmann A, Jaffe ES, Raffeld M. PTEN gene alterations in lymphoid neoplasms. Blood (1998) 92:3410-5.

90. Lenz G, Wright GW, Emre NC, Kohlhammer H, Dave SS, Davis RE, et al. Molecular subtypes of diffuse large B-cell lymphoma arise by distinct genetic pathways. Proc Natl Acad Sci USA. (2008) 105:13520-5. doi: 10.1073/pnas.0804295105

91. Pfeifer M, Grau M, Lenze D, Wenzel SS, Wolf A, Wollert-Wulf B, et al. PTEN loss defines a PI3K/AKT pathway-dependent germinal center subtype of diffuse large B-cell lymphoma. Proc Natl Acad Sci USA. (2013) 110:12420-5. doi: 10.1073/pnas.1305656110

92. Wang X, Cao X, Sun R, Tang C, Tzankov A, Zhang J, et al. Clinical significance of PTEN deletion, mutation, and loss of PTEN expression in de Novo diffuse large B-cell lymphoma. Neoplasia (2018) 20:574-93. doi: 10.1016/j.neo.2018.03.002

93. Ma Y, Zhang P, Gao Y, Fan H, Zhang M, Wu J. Evaluation of AKT phosphorylation and PTEN loss and their correlation with the resistance of rituximab in DLBCL. Int J Clin Exp Pathol. (2015) 8:14875-84.

94. Abubaker J, Bavi PP, Al-Harbi S, Siraj AK, Al-Dayel F, Uddin S, et al. PIK3CA mutations are mutually exclusive with PTEN loss in diffuse large B-cell lymphoma. Leukemia (2007) 21:2368-70. doi: 10.1038/sj.leu.2404873

95. Baohua Y, Xiaoyan Z, Tiecheng Z, Tao Q, Daren S. Mutations of the PIK3CA gene in diffuse large B cell lymphoma. Diagn Mol Pathol. (2008) 17:159-65. doi: 10.1097/PDM.0b013e31815d0588

96. Cui W, Ma M, Zheng S, Ma Z, Su L, Zhang W. PIK3CA amplification and PTEN loss in diffused large B-cell lymphoma. Oncotarget (2017) 8:66237-47. doi: 10.18632/oncotarget.19889

97. Wlodarski P, Kasprzycka M, Liu X, Marzec M, Robertson ES, Slupianek A, et al. Activation of mammalian target of rapamycin in transformed B lymphocytes is nutrient dependent but independent of Akt, mitogenactivated protein kinase/extracellular signal-regulated kinase kinase, insulin growth factor-I, and serum. Cancer Res. (2005) 65:7800-8. doi: 10.1158/0008-5472.CAN-04-4180

98. Ezell SA, Wang S, Bihani T, Lai Z, Grosskurth SE, Tepsuporn S, et al. Differential regulation of mTOR signaling determines sensitivity to AKT inhibition in diffuse large B cell lymphoma. Oncotarget (2016) 7:9163-74. doi: 10.18632/oncotarget.7036

99. Davis RE, Brown KD, Siebenlist U, Staudt LM. Constitutive nuclear factor kappaB activity is required for survival of activated B cell-like diffuse large B cell lymphoma cells. J Exp Med. (2001) 194:1861-74. doi: $10.1084 /$ jem.194.12.1861

100. Lenz G, Davis RE, Ngo VN, Lam L, George TC, Wright GW, et al. Oncogenic CARD11 mutations in human diffuse large B cell lymphoma. Science (2008) 319:1676-9. doi: 10.1126/science.1153629 
101. Compagno M, Lim WK, Grunn A, Nandula SV, Brahmachary M, Shen Q, et al. Mutations of multiple genes cause deregulation of NF-kappaB in diffuse large B-cell lymphoma. Nature (2009) 459:717-21. doi: 10.1038/nature07968

102. Ngo VN, Young RM, Schmitz R, Jhavar S, Xiao W, Lim KH, et al. Oncogenically active MYD88 mutations in human lymphoma. Nature (2011) 470:115-9. doi: 10.1038/nature09671

103. Davis RE, Ngo VN, Lenz G, Tolar P, Young RM, Romesser PB, et al. Chronic active B-cell-receptor signalling in diffuse large B-cell lymphoma. Nature (2010) 463:88-92. doi: 10.1038/nature08638

104. Gordon MS, Kanegai CM, Doerr JR, Wall R. Somatic hypermutation of the B cell receptor genes B29 (Igbeta, CD79b) and mb1 (Igalpha, CD79a). Proc Natl Acad Sci USA. (2003) 100:4126-31. doi: 10.1073/pnas.0735266100

105. Xiao G, Chan LN, Klemm L, Braas D, Chen Z, Geng H, et al. B-Cell-specific diversion of glucose carbon utilization reveals a unique vulnerability in B cell malignancies. Cell (2018) 173:470-84 e18. doi: 10.1016/j.cell.2018.02.048

106. Pasqualucci L, Khiabanian H, Fangazio M, Vasishtha M, Messina M, Holmes $\mathrm{AB}$, et al. Genetics of follicular lymphoma transformation. Cell Rep. (2014) 6:130-40. doi: 10.1016/j.celrep.2013.12.027

107. Kridel R, Sehn LH, Gascoyne RD. Pathogenesis of follicular lymphoma. J Clin Invest. (2012) 122:3424-31. doi: 10.1172/JCI63186

108. Leseux L, Hamdi SM, Al Saati T, Capilla F, Recher C, Laurent G, et al. Syk-dependent mTOR activation in follicular lymphoma cells. Blood (2006) 108:4156-62. doi: 10.1182/blood-2006-05-026203

109. Leseux L, Laurent G, Laurent C, Rigo M, Blanc A, Olive D, et al. PKC zeta mTOR pathway: a new target for rituximab therapy in follicular lymphoma. Blood (2008) 111:285-91. doi: 10.1182/blood-2007-04-085092

110. Fruchon S, Kheirallah S, Al Saati T, Ysebaert L, Laurent C, Leseux L, et al. Involvement of the Syk-mTOR pathway in follicular lymphoma cell invasion and angiogenesis. Leukemia (2012) 26:795-805. doi: 10.1038/leu.2011.248

111. Okosun J, Wolfson RL, Wang J, Araf S, Wilkins L, Castellano BM, et al. Recurrent mTORC1-activating RRAGC mutations in follicular lymphoma. Nat Genet. (2016) 48:183-8. doi: 10.1038/ng.3473

112. Lenz G, Dreyling M, Hoster E, Wörmann B, Dührsen U, Metzner B, et al. Immunochemotherapy with rituximab and cyclophosphamide, doxorubicin, vincristine, and prednisone significantly improves response and time to treatment failure, but not long-term outcome in patients with previously untreated mantle cell lymphoma: results of a prospective randomized trial of the German Low Grade Lymphoma Study Group (GLSG). J Clin Oncol. (2005) 23:1984-92. doi: 10.1200/JCO.2005.08.133

113. Jares P, Colomer D, Campo E. Genetic and molecular pathogenesis of mantle cell lymphoma: perspectives for new targeted therapeutics. Nat Rev Cancer (2007) 7:750-62. doi: 10.1038/nrc2230

114. Perez-Galan P, Dreyling M, Wiestner A. Mantle cell lymphoma: biology, pathogenesis, and the molecular basis of treatment in the genomic era. Blood (2011) 117:26-38. doi: 10.1182/blood-2010-04-189977

115. Coiffier B, Ribrag V. Exploring mammalian target of rapamycin (mTOR) inhibition for treatment of mantle cell lymphoma and other hematologic malignancies. Leuk Lymphoma (2009) 50:1916-30. doi: 10.3109/10428190903207548

116. Rudelius M, Pittaluga S, Nishizuka S, Pham TH, Fend F, Jaffe ES, et al. Constitutive activation of Akt contributes to the pathogenesis and survival of mantle cell lymphoma. Blood (2006) 108:1668-76. doi: 10.1182/blood-2006-04-015586

117. Psyrri A, Papageorgiou S, Liakata E, Scorilas A, Rontogianni D, Kontos CK, et al. Phosphatidylinositol 3'-kinase catalytic subunit alpha gene amplification contributes to the pathogenesis of mantle cell lymphoma. Clin Cancer Res. (2009) 15:5724-32. doi: 10.1158/1078-0432.CCR-08-3215

118. Choi J, Chen J, Schreiber SL, Clardy J. Structure of the FKBP12-rapamycin complex interacting with the binding domain of human FRAP. Science (1996) 273:239-42. doi: 10.1126/science.273.5272.239

119. Sarbassov DD, Ali SM, Sengupta S, Sheen JH, Hsu PP, Bagley AF, et al. Prolonged rapamycin treatment inhibits mTORC2 assembly and Akt/PKB. Mol Cell. (2006) 22:159-68. doi: 10.1016/j.molcel.2006.03.029

120. Costa LJ. Aspects of mTOR biology and the use of mTOR inhibitors in non-Hodgkin's lymphoma. Cancer Treat Rev. (2007) 33:78-84. doi: 10.1016/j.ctrv.2006.10.004

121. Haritunians T, Mori A, O’Kelly J, Luong QT, Giles FJ, Koeffler HP. Antiproliferative activity of RAD001 (everolimus) as a single agent and combined with other agents in mantle cell lymphoma. Leukemia (2007) 21:333-9. doi: 10.1038/sj.leu.2404471

122. Wanner K, Hipp S, Oelsner M, Ringshausen I, Bogner C, Peschel $\mathrm{C}$, et al. Mammalian target of rapamycin inhibition induces cell cycle arrest in diffuse large B cell lymphoma (DLBCL) cells and sensitises DLBCL cells to rituximab. Br J Haematol. (2006) 134:475-84. doi: $10.1111 / \mathrm{j} .1365-2141.2006 .06210 . \mathrm{x}$

123. Langdon WY, Harris AW, Cory S, Adams JM. The c-myc oncogene perturbs B lymphocyte development in E-mu-myc transgenic mice. Cell (1986) 47:118. doi: 10.1016/0092-8674(86)90361-2

124. Chiche J, Pommier S, Beneteau M, Mondragón L, Meynet O, Zunino $\mathrm{B}$, et al. GAPDH enhances the aggressiveness and the vascularization of non-Hodgkin's B lymphomas via NF-kappaB-dependent induction of HIF1alpha. Leukemia (2015) 29:1163-76. doi: 10.1038/leu.2014.324

125. Wall M, Poortinga G, Stanley KL, Lindemann RK, Bots M, Chan CJ, et al. The mTORC1 inhibitor everolimus prevents and treats Emu-Myclymphoma by restoring oncogene-induced senescence. Cancer Discov. (2012) 3:82-95. doi: 10.1158/2159-8290.CD-12-0404

126. Zhang J, Dominguez-Sola D, Hussein S, Lee JE, Holmes AB, Bansal $\mathrm{M}$, et al. Disruption of KMT2D perturbs germinal center B cell development and promotes lymphomagenesis. Nat Med. (2015) 21:1190-8. doi: $10.1038 / \mathrm{nm} .3940$

127. Ortega-Molina A, Boss IW, Canela A, Pan H, Jiang Y, Zhao C, et al. The histone lysine methyltransferase KMT2D sustains a gene expression program that represses B cell lymphoma development. Nat Med. (2015) 21:1199-208. doi: $10.1038 / \mathrm{nm} .3943$

128. Zhang L, Nomie K, Zhang H, Bell T, Pham L, Kadri S, et al. B-Cell Lymphoma Patient-derived xenograft models enable drug discovery and are a platform for personalized therapy. Clin Cancer Res. (2017) 23:4212-23. doi: 10.1158/1078-0432.CCR-16-2703

129. Bissler JJ, McCormack FX, Young LR, Elwing JM, Chuck G, Leonard $\mathrm{JM}$, et al. Sirolimus for angiomyolipoma in tuberous sclerosis complex or lymphangioleiomyomatosis. N Engl J Med. (2008) 358:140-51. doi: 10.1056/NEJMoa063564

130. Xu ZZ, Wang WF, Fu WB, Wang AH, Liu ZY, Chen LY, et al. Combination of rituximab and mammalian target of rapamycin inhibitor everolimus (RAD001) in diffuse large B-cell lymphoma. Leuk Lymphoma (2014) 55:1151-7. doi: 10.3109/10428194.2013.823492

131. Bi C, Zhang X, Lu T, Zhang X, Wang X, Meng B, et al. Inhibition of 4EBP phosphorylation mediates the cytotoxic effect of mechanistic target of rapamycin kinase inhibitors in aggressive B-cell lymphomas. Haematologica (2017) 102:755-64. doi: 10.3324/haematol.2016.159160

132. Pallet N, Legendre C. Adverse events associated with mTOR inhibitors. Expert Opin Drug Saf. (2013) 12:177-86. doi: 10.1517/14740338.2013.752814

133. Lee JS, Vo TT, Fruman DA. Targeting mTOR for the treatment of B cell malignancies. Br J Clin Pharmacol. (2016) 82:1213-28. doi: 10.1111/bcp.12888

134. Choo AY, Yoon SO, Kim SG, Roux PP, Blenis J. Rapamycin differentially inhibits $\mathrm{S} 6 \mathrm{Ks}$ and $4 \mathrm{E}-\mathrm{BP} 1$ to mediate cell-type-specific repression of mRNA translation. Proc Natl Acad Sci USA. (2008) 105:17414-9. doi: 10.1073/pnas.0809136105

135. Kang SA, Pacold ME, Cervantes CL, Lim D, Lou HJ, Ottina K, et al. mTORC1 phosphorylation sites encode their sensitivity to starvation and rapamycin. Science (2013) 341:1236566. doi: 10.1126/science.1236566

136. Ansell SM, Tang H, Kurtin PJ, Koenig PA, Inwards DJ, Shah $\mathrm{K}$, et al. Temsirolimus and rituximab in patients with relapsed or refractory mantle cell lymphoma: a phase 2 study. Lancet Oncol. (2011) 12:361-8. doi: 10.1016/S1470-2045(11)7 0062-6

137. Barnes JA, Jacobsen E, Feng Y, Freedman A, Hochberg EP, LaCasce AS, et al. Everolimus in combination with rituximab induces complete responses in heavily pretreated diffuse large B-cell lymphoma. Haematologica (2013) 98:615-9. doi: 10.3324/haematol.2012.075184

138. Jazirehi AR, Vega MI, Chatterjee D, Goodglick L, Bonavida B. Inhibition of the Raf-MEK1/2-ERK1/2 signaling pathway, Bcl-xL down-regulation, and chemosensitization of non-Hodgkin's lymphoma $B$ cells by Rituximab. Cancer Res (2004) 64:7117-26. doi: 10.1158/0008-5472.CAN-0 3-3500 
139. Alas S, Bonavida B. Rituximab inactivates signal transducer and activation of transcription 3 (STAT3) activity in B-non-Hodgkin's lymphoma through inhibition of the interleukin 10 autocrine/paracrine loop and results in down-regulation of $\mathrm{Bcl}-2$ and sensitization to cytotoxic drugs. Cancer Res. (2001) 61:5137-44.

140. Byrd JC, Kitada S, Flinn IW, Aron JL, Pearson M, Lucas D, et al. The mechanism of tumor cell clearance by rituximab in vivo in patients with B-cell chronic lymphocytic leukemia: evidence of caspase activation and apoptosis induction. Blood (2002) 99:1038-43. doi: 10.1182/blood.V99.3.1038

141. Kheirallah S, Caron P, Gross E, Quillet-Mary A, Bertrand-Michel J, Fournié JJ, et al. Rituximab inhibits B-cell receptor signaling. Blood (2010) 115:98594. doi: 10.1182/blood-2009-08-237537

142. Foran JM, Rohatiner AZ, Cunningham D, Popescu RA, Solal-Celigny P, Ghielmini M, et al. European phase II study of rituximab (chimeric antiCD20 monoclonal antibody) for patients with newly diagnosed mantle-cell lymphoma and previously treated mantle-cell lymphoma, immunocytoma, and small B-cell lymphocytic lymphoma. J Clin Oncol. (2000) 18:317-24. doi: 10.1200/JCO.2000.18.2.317

143. Ghielmini M, Schmitz SF, Cogliatti S, Bertoni F, Waltzer U, Fey MF, et al. Effect of single-agent rituximab given at the standard schedule or as prolonged treatment in patients with mantle cell lymphoma: a study of the Swiss Group for Clinical Cancer Research (SAKK). J Clin Oncol. (2005) 234:705-11. doi: 10.1200/JCO.2005.04.164

144. Coiffier B, Haioun C, Ketterer N, Engert A, Tilly H, Ma D et al. Rituximab (anti-CD20 monoclonal antibody) for the treatment of patients with relapsing or refractory aggressive lymphoma: a multicenter phase II study. Blood (1998) 92:1927-32.

145. Johnston PB, LaPlant B, McPhail E, Habermann TM, Inwards DJ, Micallef IN, et al. Everolimus combined with R-CHOP-21 for new, untreated, diffuse large B-cell lymphoma (NCCTG 1085 [Alliance]): safety and efficacy results of a phase 1 and feasibility trial. Lancet Haematol. (2016) 3:e309-16. doi: 10.1016/S2352-3026(16)30040-0

146. Mathews Griner LA, Guha R, Shinn P, Young RM, Keller JM, Liu D, et al. High-throughput combinatorial screening identifies drugs that cooperate with ibrutinib to kill activated B-cell-like diffuse large B-cell lymphoma cells. Proc Natl Acad Sci USA. (2014) 111:2349-54. doi: 10.1073/pnas.1311846111

147. Ezell SA, Mayo M, Bihani T, Tepsuporn S, Wang S, Passino M, et al. Synergistic induction of apoptosis by combination of BTK and dual mTORC1/2 inhibitors in diffuse large B cell lymphoma. Oncotarget (2014) 5:4990-5001. doi: 10.18632/oncotarget.2071

148. Gupta M, Ansell SM, Novak AJ, Kumar S, Kaufmann SH, Witzig TE. Inhibition of histone deacetylase overcomes rapamycin-mediated resistance in diffuse large B-cell lymphoma by inhibiting Akt signaling through mTORC2. Blood (2009) 114:2926-35. doi: 10.1182/blood-2009-05-220889

149. Yazbeck VY, Buglio D, Georgakis GV, Li Y, Iwado E, Romaguera JE, et al. Temsirolimus downregulates p21 without altering cyclin D1 expression and induces autophagy and synergizes with vorinostat in mantle cell lymphoma. Exp Hematol. (2008) 36:443-50. doi: 10.1016/j.exphem.2007.12.008

150. Oki Y, Buglio D, Fanale M, Fayad L, Copeland A, Romaguera J, et al. Phase I study of panobinostat plus everolimus in patients with relapsed or refractory lymphoma. Clin Cancer Res. (2013) 19:6882-90. doi: 10.1158/1078-0432.CCR-13-1906

151. Witzens-Harig M, Memmer ML, Dreyling M, Hess G. A phase I/II trial to evaluate the safety, feasibility and activity of salvage therapy consisting of the mTOR inhibitor Temsirolimus added to standard therapy of Rituximab and DHAP for the treatment of patients with relapsed or refractory diffuse large cell B-Cell lymphoma - the STORM trial. BMC Cancer (2013) 13:308. doi: 10.1186/1471-2407-13-308

152. Teachey DT, Sheen C, Hall J, Ryan T, Brown VI, Fish J, et al. mTOR inhibitors are synergistic with methotrexate: an effective combination to treat acute lymphoblastic leukemia. Blood (2008) 112:2020-3. doi: 10.1182/blood-2008-02-137141

153. Farge T, Saland E, de Toni F, Aroua N, Hosseini M, Perry R, et al. Chemotherapy-resistant human acute myeloid leukemia cells are not enriched for leukemic stem cells but require oxidative metabolism. Cancer Discov. (2017) 7:716-35. doi: 10.1158/2159-8290.CD-16-0441.
154. Bost F, Decoux-Poullot AG, Tanti JF, Clavel S. Energy disruptors: rising stars in anticancer therapy? Oncogenesis (2016) 5:e188. doi: 10.1038/oncsis.2015.46

155. Owen MR, Doran E, Halestrap AP. Evidence that metformin exerts its anti-diabetic effects through inhibition of complex 1 of the mitochondrial respiratory chain. Biochem J. (2000) 348(Pt. 3):607-14. doi: 10.1042/0264-6021:3480607

156. Zhou G, Myers R, Li Y, Chen Y, Shen X, Fenyk-Melody J, et al. Role of AMPactivated protein kinase in mechanism of metformin action. J Clin Invest. (2001) 108:1167-74. doi: 10.1172/JCI13505

157. El-Mir MY, Nogueira V, Fontaine E, Averet N, Rigoulet M, Leverve X. Dimethylbiguanide inhibits cell respiration via an indirect effect targeted on the respiratory chain complex I. J Biol Chem. (2000) 275:223-8. doi: $10.1074 /$ jbc.275.1.223

158. Zakikhani M, Dowling R, Fantus IG, Sonenberg N, Pollak M. Metformin is an AMP kinase-dependent growth inhibitor for breast cancer cells. Cancer Res. (2006) 66:10269-73. doi: 10.1158/0008-5472.CAN-06-1500

159. Ben Sahra I, Regazzetti C, Robert G, Laurent K, Le Marchand-Brustel Y, Auberger P, et al. Metformin, independent of AMPK, induces mTOR inhibition and cell-cycle arrest through REDD1. Cancer Res. (2011) 71:436672. doi: 10.1158/0008-5472.CAN-10-1769

160. Wheaton WW, Weinberg SE, Hamanaka RB, Soberanes S, Sullivan LB, Anso E, et al. Metformin inhibits mitochondrial complex I of cancer cells to reduce tumorigenesis. Elife (2014) 3:e02242. doi: 10.7554/eLife.02242

161. Chukkapalli V, Gordon LI, Venugopal P, Borgia JA, Karmali R. Metabolic changes associated with metformin potentiates Bcl-2 inhibitor, Venetoclax, and CDK9 inhibitor, BAY1143572 and reduces viability of lymphoma cells. Oncotarget (2018) 9:21166-81. doi: 10.18632/oncotarget.24989

162. Howell JJ, Hellberg K, Turner M, Talbott G, Kolar MJ, Ross DS, et al. Metformin inhibits hepatic mTORC1 signaling via dose-dependent mechanisms involving AMPK and the TSC complex. Cell Metab. (2017) 25:463-71. doi: 10.1016/j.cmet.2016.12.009

163. Dowling RJ, Zakikhani M, Fantus IG, Pollak M, Sonenberg N. Metformin inhibits mammalian target of rapamycin-dependent translation initiation in breast cancer cells. Cancer Res. (2007) 67:10804-12. doi: 10.1158/0008-5472.CAN-07-2310

164. Shi WY, Xiao D, Wang L, Dong LH, Yan ZX, Shen ZX, et al. Therapeutic metformin/AMPK activation blocked lymphoma cell growth via inhibition of mTOR pathway and induction of autophagy. Cell Death Dis. (2012) 3:e275. doi: $10.1038 /$ cddis. 2012.13

165. Hulea L, Gravel SP, Morita M, Cargnello M, Uchenunu O, Im YK, et al. Translational and HIF-1alpha-dependent metabolic reprogramming underpin metabolic plasticity and responses to kinase inhibitors and biguanides. Cell Metab. (2018) doi: 10.1016/j.cmet.2018.09.001. [Epub ahead of print].

166. Alkhatib Y, Abdel Rahman Z, Kuriakose P. Clinical impact of metformin in diabetic diffuse large B-cell lymphoma patients: a case-control study. Leuk Lymphoma (2016) 58:1130-4. doi: 10.1080/10428194.2016.1239822

167. Pusapati RV, Daemen A, Wilson C, Sandoval W, Gao M, Haley B, et al. mTORC1-Dependent Metabolic Reprogramming Underlies Escape from Glycolysis Addiction in Cancer Cells. Cancer Cell (2016) 29:548-62. doi: 10.1016/j.ccell.2016.02.018

168. Fantin VR, St-Pierre J, Leder P. Attenuation of LDH-A expression uncovers a link between glycolysis, mitochondrial physiology, and tumor maintenance. Cancer Cell (2006) 9:425-34. doi: 10.1016/j.ccr.2006.04.023

169. Le A, Cooper CR, Gouw AM, Dinavahi R, Maitra A, Deck LM, et al. Inhibition of lactate dehydrogenase A induces oxidative stress and inhibits tumor progression. Proc Natl Acad Sci USA. (2010) 107:2037-42. doi: 10.1073/pnas.0914433107

170. Le Floch R, Chiche J, Marchiq I, Naiken T, Ilc K, Murray CM, et al. CD147 subunit of lactate/H+ symporters MCT1 and hypoxia-inducible MCT4 is critical for energetics and growth of glycolytic tumors. Proc Natl Acad Sci USA. (2011) 108:16663-8. doi: 10.1073/pnas.1106123108

171. Tanaka K, Sasayama T, Irino Y, Takata K, Nagashima H, Satoh N, et al. Compensatory glutamine metabolism promotes glioblastoma resistance to mTOR inhibitor treatment. J Clin Invest. (2015) 125:1591-602. doi: 10.1172/JCI78239 
172. Gross MI, Demo SD, Dennison JB, Chen L, Chernov-Rogan T, Goyal B, et al. Antitumor activity of the glutaminase inhibitor CB-839 in triple-negative breast cancer. Mol Cancer Ther. (2014) 13:890-901. doi: 10.1158/1535-7163.MCT-13-0870

173. Jacque N, Ronchetti AM, Larrue C, Meunier G, Birsen R, Willems L, et al. Targeting glutaminolysis has antileukemic activity in acute myeloid leukemia and synergizes with BCL-2 inhibition. Blood (2015) 126:1346-56. doi: 10.1182/blood-2015-01-621870

174. Shroff EH, Eberlin LS, Dang VM, Gouw AM, Gabay M, Adam SJ, et al. MYC oncogene overexpression drives renal cell carcinoma in a mouse model through glutamine metabolism. Proc Natl Acad Sci USA. (2015) 112:6539-44. doi: $10.1073 /$ pnas. 1507228112

175. Iyer G, Hanrahan AJ, Milowsky MI, Al-Ahmadie H, Scott SN, Janakiraman $\mathrm{M}$, et al. Genome sequencing identifies a basis for everolimus sensitivity. Science (2012) 338:221. doi: 10.1126/science.12 26344

176. Wagle N, Grabiner BC, Van Allen EM, Hodis E, Jacobus S, Supko JG, et al. Activating $\mathrm{mTOR}$ mutations in a patient with an extraordinary response on a phase I trial of everolimus and pazopanib. Cancer Discov. (2013) 4:546-53. doi: 10.1158/2159-8290.CD-13-0353
177. Grabiner BC, Nardi V, Birsoy K, Possemato R, Shen K, Sinha S, et al. A diverse array of cancer-associated MTOR mutations are hyperactivating and can predict rapamycin sensitivity. Cancer Discov. (2014) 4:554-63. doi: 10.1158/2159-8290.CD-13-0929

178. Fiorini C, Massari F, Pedron S, Sanavio S, Ciccarese C, Porcaro AB, et al. Methods to identify molecular expression of mTOR pathway: a rationale approach to stratify patients affected by clear cell renal cell carcinoma for more likely response to mTOR inhibitors. Am J Cancer Res. (2014) 4:907-15.

Conflict of Interest Statement: The authors declare that the research was conducted in the absence of any commercial or financial relationships that could be construed as a potential conflict of interest.

Copyright (c) 2018 Ricci and Chiche. This is an open-access article distributed under the terms of the Creative Commons Attribution License (CC BY). The use, distribution or reproduction in other forums is permitted, provided the original author(s) and the copyright owner(s) are credited and that the original publication in this journal is cited, in accordance with accepted academic practice. No use, distribution or reproduction is permitted which does not comply with these terms. 